Western Washington University

Western CEDAR

Summer 2019

\title{
The effects of hallux valgus and walking speed on dynamic balance in older adults
}

Carolyn E. Barbee

Western Washington University, cbarbee216@gmail.com

Follow this and additional works at: https://cedar.wwu.edu/wwuet

Part of the Kinesiology Commons

\section{Recommended Citation}

Barbee, Carolyn E., "The effects of hallux valgus and walking speed on dynamic balance in older adults" (2019). WWU Graduate School Collection. 890.

https://cedar.wwu.edu/wwuet/890

This Masters Thesis is brought to you for free and open access by the WWU Graduate and Undergraduate Scholarship at Western CEDAR. It has been accepted for inclusion in WWU Graduate School Collection by an authorized administrator of Western CEDAR. For more information, please contact westerncedar@wwu.edu. 


\title{
THE EFFECTS OF HALLUX VALGUS AND WALKING SPEED ON DYNAMIC BALANCE IN OLDER ADULTS
}

\author{
By \\ Carolyn Barbee \\ Accepted in Partial Completion \\ of the Requirements for the Degree \\ Master of Science
}

ADVISORY COMMITTEE

Dr. Harsh H. Buddhadev, Chair

Dr. Gordon R. Chalmers

Dr. David N. Suprak

GRADUATE SCHOOL

Dr. Kathleen L. Kitto, Dean 


\section{Master's Thesis}

In presenting this thesis in partial fulfillment of the requirements for a master's degree at Western Washington University, I grant to Western Washington University the non-exclusive royalty-free right to archive, reproduce, distribute, and display the thesis in any and all forms, including electronic format, via any digital library mechanisms maintained by WWU.

I represent and warrant this is my original work, and does not infringe or violate any rights of others. I warrant that I have obtained written permissions from the owner of any third party copyrighted material included in these files.

I acknowledge that I retain ownership rights to the copyright of this work, including but not limited to the right to use all or part of this work in future works, such as articles or books.

Library users are granted permission for individual, research and non-commercial reproduction of this work for educational purposes only. Any further digital posting of this document requires specific permission from the author.

Any copying or publication of this thesis for commercial purposes, or for financial gain, is not allowed without my written permission.

Carolyn Barbee

$7 / 5 / 2019$ 
The effects of hallux valgus and walking speed on dynamic balance in older adults

\author{
A Thesis \\ Presented to \\ The Faculty of \\ Western Washington University
}

In Partial Fulfillment

Of the Requirements for the Degree

Master of Science

by

Carolyn Barbee

June 2019 


\begin{abstract}
Hallux valgus (HV) contributes to deficits in static balance and increased fall risk in older adults. Very limited research has examined dynamic balance deficits in walking in this population. These individuals generally walk slowly, as balance challenge is lesser at slow speeds. The purpose of this study was to examine dynamic balance in older adults with HV compared to healthy controls at controlled slow and fast speeds. Nineteen older adults with HV and 13 healthy controls completed 5 continuous walking trials at 1.0 and $1.3 \mathrm{~m} \cdot \mathrm{s}^{-1}$ as whole body marker position and ground reaction force data were captured. Dynamic balance was evaluated using whole body center of mass (COM) and center of pressure (COP) inclination angles (IA) and duration of double support. There were no differences in measures of dynamic balance between older adults with and without HV at slow and fast speeds. At the faster speed, the peak sagittal plane COM-COP IA increased and the double support duration decreased, while the peak frontal plane COM-COP IA were not affected. Older adults with HV do not exhibit deficits in dynamic balance during continuous walking at comfortable speeds when compared to healthy older adults.
\end{abstract}

Keywords: Bunions, Center of mass, Center of pressure, Inclination angles 


\section{Acknowledgements}

First and foremost, I must thank my thesis chair and mentor, Dr. Harsh Buddhadev. During my time at Western Washington University, Dr. Buddhadev has put his trademark energy towards shaping me into a sound researcher, writer, and academic. He has been my guide, my sounding board, and the biggest supporter of my professional goals. My academic accomplishments are, and will continue to be, a reflection of the incredible mentor I was lucky to have. I would also like to thank my committee members, Dr. Dave Suprak and Dr. Gordon Chalmers. During my time at Western, I was fortunate to serve not only as Dr. Suprak's student, but also as his teaching assistant. His expertise, support, and guidance have been instrumental in my development as a competent biomechanist. Dr. Chalmers' expertise on motor control and balance was invaluable to this project. However, what I find myself most grateful for are his dedication to teaching me how to conduct focused, meaningful research and critically examine research from all perspectives. This committee did an incredible job supporting me and holding me to a high standard of excellence and integrity, and for that I am exceedingly grateful.

I would like to thank the rest of the faculty and graduate cohort within the WWU Kinesiology Department for their camaraderie, support, and intellectual stimulation. Thank you for pushing me to be better, keeping me humble, and reminding me not to take myself too seriously. A special thanks goes out to my research assistants: Paul Sage, Sarah Perry, Katie Olinger, Ryan Cupp, Ciera Briggs, Jordan Orr, and Maxx Antush. Thank you for all your hard work in helping make this project happen - I could not have done this without you. Thank you to my Bellingham community - especially the Whatcom YMCA and the Bellingham Senior Activities Center - who have been my cheering section throughout this project and my constant reminder of why the hard work I put into this degree is all worth it. I would like to thank my family, who has always supported my dreams and drive, even when it was hard or scary. I always feel and appreciate your love and support, even from thousands of miles away. Lastly, I would like to thank my two best friends in the world, Grace Cobbins and Emily Spiwak. You two are my compass in this world, and I would be absolutely lost without you. 


\section{Table of Contents}

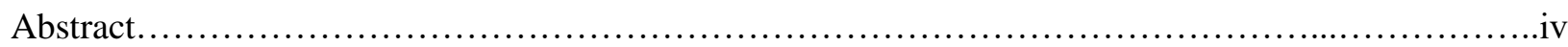

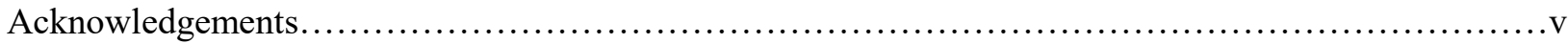

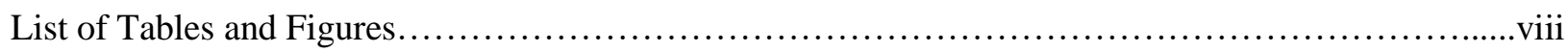

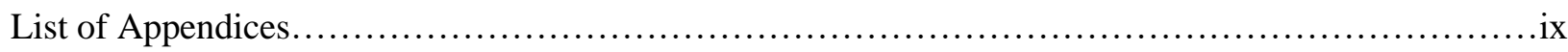

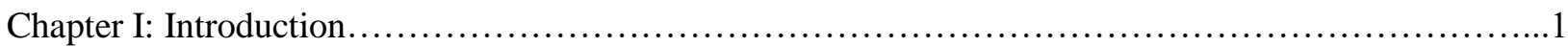

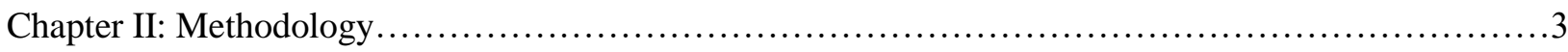

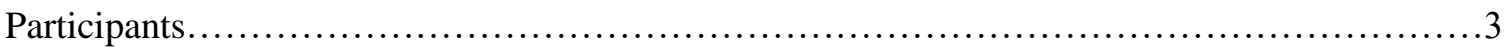

Data collection..................................................................4

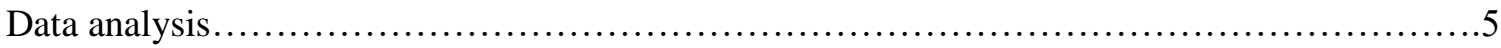

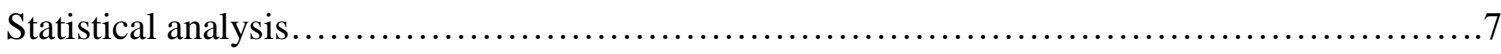

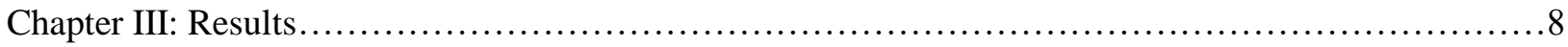

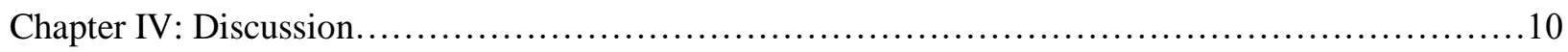

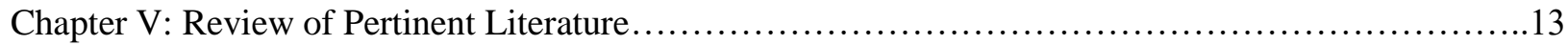

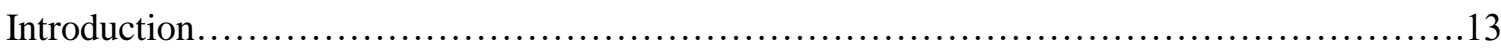

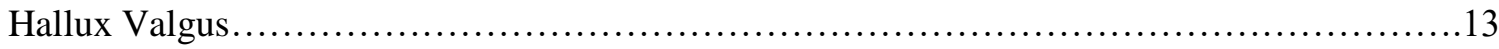

Musculoskeletal and ligamentous contributions to hallux valgus.....................14

Morphological differences associated with hallux valgus...........................14

The contributions of footwear to the development of hallux valgus...................15

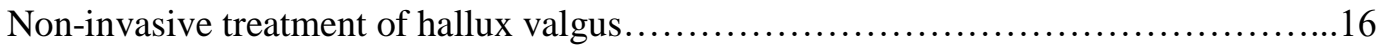

Surgical treatment of hallux valgus.............................................16

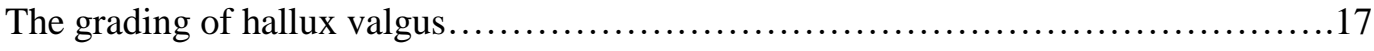

The Manchester Scale.....................................................17

The impacts of hallux valgus on quality of life...................................18

The effect of hallux valgus on static balance.......................................19

The effect of hallux valgus on spatiotemporal gait parameters......................20

The effect of hallux valgus on dynamic balance and fall risk........................20

Dynamic Balance in Walking in Older Adults..........................................22

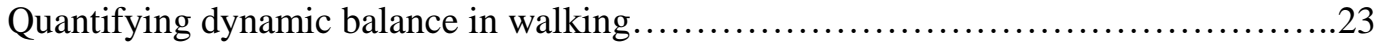

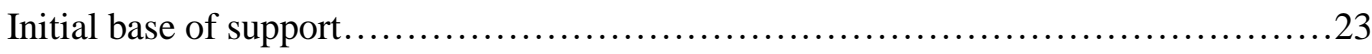


Double support duration................................................... 23

Center of mass velocity....................................................... 24

Center of mass-center of pressure separation..................................24

Center of mass-center of pressure inclination angles.............................25

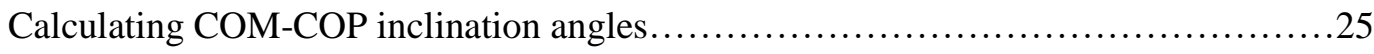

Typical values for COM-COP inclination angles................................28

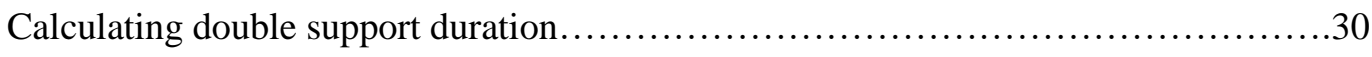

Normal values for double support duration......................................30

Double support duration when hallux valgus is present..............................31

The effect of walking speed on measures of dynamic balance.........................33

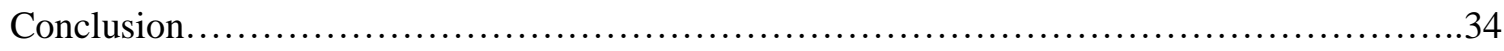

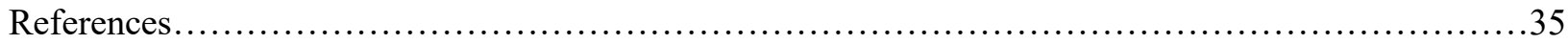

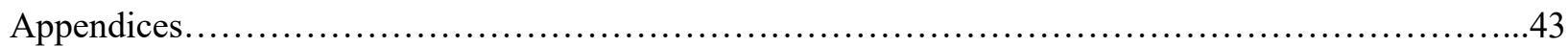




\section{List of Tables and Figures}

Figure 1. Calculation of COM-COP inclination angle.....................................6, 26

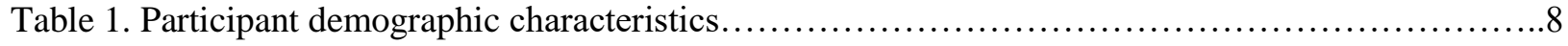

Table 2. Gait parameters, double support duration, and COM-COP IA data.......................... 9

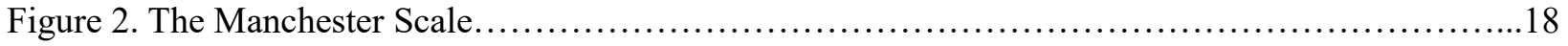

Figure 3. VICON PlugIn Gait Full Body marker model...........................................28

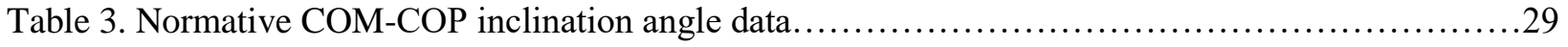

Table 4. Normative double support duration data................................................ 32 


\section{List of Appendices}

Appendix A: Informed Consent..............................................43

Appendix B: Gait \& Posture Author Guidelines.........................................45 


\section{Chapter I}

\section{Introduction}

Older adults exhibit a decreased capacity to maintain balance during dynamic tasks such as walking [1]. This decline in dynamic balance may explain why older adults tend to have an increased risk for falls [2]. With advancing age, foot deformities such as hallux valgus (HV) also become increasingly prevalent $[3,4]$, which further increases fall risk in older adults [5,6]. HV is also known to adversely affect static balance [7-9] and habitual walking speed [10,11]. These findings suggest that dynamic balance during walking may be affected in older adults with HV.

The relationship between HV and dynamic balance during walking in older adults has not been sufficiently investigated. Only two studies have examined the effect of HV on dynamic balance during walking in older adults. Mickle et al. [12] and Sadra et al.[13] both found that double support duration, a spatiotemporal gait parameter associated with dynamic balance in walking, was not different between HV

subjects and controls. However, double support duration alone is not considered to be a sensitive measure of dynamic balance although the need for dynamic balance is greatest in the double support phases of walking, when weight is rapidly transferred from the trailing leg to the leading leg $[14,15]$. Double support duration is not a sensitive enough measure because it does not take into account the relationship between whole body center of mass (COM) and base of support. The interaction of whole body COM, center of pressure (COP), and the inclination angle (IA) between these two points (i.e. COM and COP) has been shown to be a more sensitive measure of balance in walking than double support duration $[16,17]$. Peak COM-COP IA occur near the instants of weight acceptance and transfer during the double support phases and thus provide a more precise assessment of dynamic balance. No studies to date have examined dynamic balance in $\mathrm{HV}$ using measures of COM and COP interactions.

Dynamic balance challenge increases with walking speed, and thus walking speed should be controlled when assessing dynamic balance. Research indicates that walking speed independently affects double support duration [18] and COM-COP IA [19,20]. As walking speed increases, the double support 
phase shortens in healthy subjects [18]. Similarly, peak anterior and posterior COM-COP IA increase while peak medial IA decreases with increasing walking speed [19,20]. Older adults with HV often walk at slower preferred speeds than healthy, age-matched controls [10,11]. The two studies which examined dynamic balance during walking in older individuals with HV assessed double support duration at slower, preferred speeds $[12,13]$. The effect of HV on walking balance at controlled, faster speeds has not yet been examined. The deficits in balance may become more apparent in individuals with HV if assessments are performed at faster walking speeds using more sensitive measures of analysis (i.e. anterior, posterior, and medial COM-COP IA).

There has been limited assessment of the cumulative effects of age and HV on walking balance in the gait of older adults. Deficits in dynamic balance during walking have not been examined in older adults with HV under experimentally-controlled slow and fast speed conditions using sensitive measures of balance such as peak COM-COP IA. Therefore, the purpose of this study was to evaluate dynamic balance evaluated via peak COM-COP IA during walking in older adults with HV under experimentallycontrolled slow and fast walking speeds, specifically near the double support phase near the instants of weight acceptance and transfer. We hypothesized that individuals with HV compared to healthy age- and sex-matched controls would demonstrate greater deficits in dynamic balance, displaying increased medial and decreased anterior and posterior peak COM-COP IA for the fast speed condition, but that these peak IA would not be affected at slower speeds. 


\section{Chapter II}

\section{Methods}

\section{Participants}

Nineteen older community-dwelling adults with HV and 19 controls participated in this study (age range 60-85 years). Since no previous research has examined dynamic balance using COM-COP IA measures in older adults with HV, a statistical power analysis was conducted using GPower 3.1 software to determine the appropriate sample size. To achieve a statistical power of 0.8 for a medium effect size (Cohen's $\mathrm{f}=0.25$ ) age $\mathrm{x}$ speed interaction, a sample size of 34 participants ( 17 participants per group) was needed.

All participants were community-dwelling individuals capable of walking unassisted continuously for a minimum of 10 minutes without resting. Using the Manchester Scale, all participants (i.e. HV and controls) were evaluated to determine the presence and grade of HV [21]. Participants were included in the experimental HV group if the degree of deformity assessed was at either moderate or severe, class 2 or class 3, respectively. Prior research has shown that balance is adversely affected and fall risk is greater in older adults with a moderate-to-severe grade of HV [5,6,10]. HV participants were included in the study if they exhibited the deformity without the presence of disabling pain which affects walking. Prior research has shown that approximately $70 \%-88 \%$ of individuals with moderate-to-severe HV do not experience excessive pain [22,23]. Control participants were also evaluated using the Manchester Scale and included if they did not have HV, otherwise known as a class 0 categorization. Individuals with any orthopedic or neurological conditions affecting balance and walking were excluded from the study. Also, individuals who received surgical correction for HV were also excluded. Western Washington University Institutional Review Board approved the study and all participants provided a written informed consent prior to participation. 


\section{Data collection}

All participants completed a single, one-hour testing session. Upon arrival at the lab, participants filled out a health history and physical activity questionnaire. Prior to trials, each of the subject's feet were visually inspected in a weight-bearing position by a single investigator (CB), and classified according to the Manchester Scale. Previous research has shown that the grade of HV can be reliably classified using this visual scale [24]. The Manchester Scale has been shown to be a highly reliable (i.e. high intra- and inter-rater reliability) and valid method for classifying HV for research purposes, and has been used frequently in the literature [3,21-28]. Studies have shown that the Manchester Scale has a high level of concurrent criterion validity when compared to criterion radiographic assessment [29]. After HV assessment, participants changed into spandex clothes provided by the investigators.

Anthropometric measurements of body height, body mass, inter-anterior superior iliac spine distance, and bilateral leg length, knee width, ankle width, shoulder offset width, elbow width, wrist width, and hand thickness were taken. Next, 39 reflective markers were placed on the participant's skin and spandex clothes according to the full body VICON PlugIn Gait model guidelines. VICON PlugIn Gait model was chosen for the current study because it has been extensively used to quantify whole body center of mass (COM) position [15,19,20,30-35]. A 10-camera VICON motion capture system (Centennial, CO, USA) and two AMTI in-ground forceplates (Watertown, MA, USA) captured three dimensional marker position and ground reaction force data synchronously at $100 \mathrm{~Hz}$ and $1000 \mathrm{~Hz}$, respectively. A static calibration trial was completed during which the participants were instructed to stand stationary on a single forceplate in the "motorcycle pose" according to VICON PlugIn Gait model guidelines. 
After the static trial, dynamic walking trials were completed at two experimentally controlled speeds of $1.0 \mathrm{~m} \cdot \mathrm{s}^{-1}$ and $1.3 \mathrm{~m} \cdot \mathrm{s}^{-1}$ in a random order. The slower speed, $1.0 \mathrm{~m} \cdot \mathrm{s}^{-1}$, was selected as it is reported to be the typical natural gait of older adults exhibiting moderate-to-severe HV [10-12].

Similarly, the faster speed, $1.3 \mathrm{~m} \cdot \mathrm{s}^{-1}$, was selected as it is the typical natural gait of healthy older adults [36-38]. Participants were given 3-5 familiarization trials to get acclimated to walking at each speed before trials were collected. After familiarization, data were collected for five trials for each walking speed condition. Walking speed was computed immediately after each trial (using the data for one-stride length as the participant walked across the capture zone) to check if it was within $\pm 3 \%$ of the target speed. A trial was accepted if the subject was able to 1 ) achieve the targeted speed within the $\pm 3 \%$ range of error with a natural gait, 2) strike the correct forceplate without making any visible alterations to stride pattern, and 3) strike the forceplates such that the leg exhibiting the greatest degree of HV was the leading leg [39].

\section{Data analysis}

Marker position and ground reaction force data were low pass filtered at $8 \mathrm{~Hz}$ using a 4 th order Butterworth filter [40-42]. Basic spatiotemporal variables such as walking speed, stride length, step width, cadence, and double support duration were computed from the filtered data. Using marker position data and Dempster's equations [43], each segment's center of mass and the whole body COM were computed using VICON Plug-in gait post capture pipeline [15,19,20,29-34]. Instantaneous COM position coordinates were determined for the entire gait cycle. Center of pressure (COP) coordinates were computed from forceplate ground reaction force and moment data. Because each forceplate provides its own COP data, there was a need to determine resultant COP which combines data from both forceplates during the double-support phase. This was accomplished using the equation below [14-16,44]: 


$$
C O P_{R}=C O P_{1} \frac{F_{Z 1}}{\left(F_{Z 2}+F_{Z 1}\right)}+C O P_{2} \frac{F_{Z 2}}{\left(F_{Z 1}+F_{Z 2}\right)}
$$

where $C O P_{R}$ is the resultant $\mathrm{COP}, \mathrm{COP}_{1}$ and $\mathrm{COP}_{2}$ are the $\mathrm{COP}$ coordinates from the respective forceplates, and $F z_{1}$ and $F z_{2}$ are the vertical ground reaction forces from each respective forceplate.

Instantaneous COM and COP position data were then used to calculate the IA for the frontal (medial) and sagittal (anterior and posterior) planes. The calculation of these angles has been described previously [16]. Briefly, the equation used to compute AP and ML COM-COP IA is provided below (Figure 1):

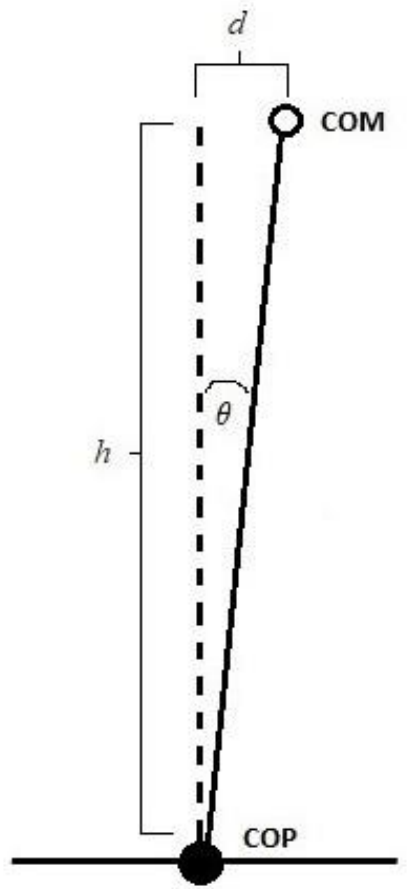

$$
\theta=\tan ^{-1}(d / h)
$$

Figure 1. The calculation of the center of mass-center of pressure IA uses the height of the COM $(h)$ and the horizontal separation of the center of mass and center of pressure $(d)$ to calculate the angle $(\theta)$, as shown above. This model can be applied to either the sagittal (anterior-posterior) or the frontal (mediolateral) planes.

where $\theta$ is the IA, $d$ is the horizontal separation between the COM and COP, and $h$ is the vertical height of the COM from the ground. Instantaneous COM-COP IA were computed over a gait cycle, and peak anterior, posterior, and medial values were identified for further analysis. 


\section{Statistical analysis}

The independent variables for this experiment were the presence of HV and walking speed. The primary dependent variables examined were peak anterior, posterior, and medial COM-COP IA, and the double support duration during which the foot exhibiting HV is the push-off leg. The secondary dependent variables were stride length and step width. A mixed model ANOVA with repeated measures for speed was used to examine the effect of HV on the dependent variables. Alpha was set a priori to 0.05 . Effect sizes were calculated as partial eta squared $\left(\eta_{\mathrm{p}}{ }^{2}\right)$, where, $\eta_{\mathrm{p}}{ }^{2}>0.01$ was small, $\eta_{\mathrm{p}}{ }^{2}>0.06$ was medium, and $\eta_{\mathrm{p}}^{2}>0.15$ was large effect size [45]. All statistical procedures were performed using SPSS (Version 23). 


\section{Chapter III}

\section{Results}

Demographic characteristics are presented in Table 1. The hallux valgus and control group participants were not significantly different in age, height, mass, and amount of moderate-to-vigorous physical activity they engaged in regularly on a weekly basis. A majority of the participants in the hallux valgus group (14/19) had grade 3 severity of the condition.

Table 1. Participant demographic characteristics

\begin{tabular}{ccccc}
\hline & Hallux Valgus $(\boldsymbol{n = 1 9 )}$ & Controls $(\boldsymbol{n = 1 9})$ & $\boldsymbol{t}$-value & $\begin{array}{c}\boldsymbol{p} \text { - } \\
\text { value }\end{array}$ \\
\hline Sex & 13 females & 13 females & & \\
Grade of Hallux Valgus & $2.7 \pm 0.5$ & 0 & & \\
Age (years) & $71.4 \pm 5.6$ & $68.6 \pm 5.5$ & $\mathrm{t}_{36}=1.557$ & 0.128 \\
Height (cm) & $164.6 \pm 11.9$ & $165.8 \pm 11.0$ & $\mathrm{t}_{36}=-0.324$ & 0.784 \\
Mass (kg) & $68.5 \pm 10.3$ & $71.4 \pm 12.7$ & $\mathrm{t}_{36}=-0.784$ & 0.438 \\
$\begin{array}{c}\text { Moderate to vigorous physical } \\
\text { activity (minutes/week) }\end{array}$ & $464.4 \pm 382.0$ & $455.1 \pm 386.0$ & $\mathrm{t}_{36}=0.074$ & 0.941 \\
\hline
\end{tabular}

There were no group-speed interactions or differences between groups for any of the spatiotemporal variables and peak COM-COP IA. With an increase in speed there was an increase in stride length and anterior and posterior COM-COP IA, a decrease in double support duration, but no significant differences in step width and medial COM-COP IA (Table 2). 
Table 2. Gait parameters, double support duration, and COM-COP IA

\begin{tabular}{|c|c|c|c|c|c|c|c|}
\hline & \multicolumn{2}{|c|}{ Hallux Valgus } & \multicolumn{2}{|c|}{ Controls } & \multirow{2}{*}{$\begin{array}{l}\text { Group main } \\
\text { effect }\end{array}$} & \multirow{2}{*}{ Speed main effect } & \multirow{2}{*}{$\begin{array}{l}\text { Group-speed } \\
\text { interaction }\end{array}$} \\
\hline & $1.0 \mathrm{~m} \cdot \mathrm{s}^{-1}$ & $1.3 \mathrm{~m} \cdot \mathrm{s}^{-1}$ & $1.0 \mathrm{~m} \cdot \mathrm{s}^{-1}$ & $1.3 \mathrm{~m} \cdot \mathrm{s}^{-1}$ & & & \\
\hline $\begin{array}{l}\text { Stride length } \\
\qquad(\mathrm{m})\end{array}$ & $1.18 \pm 0.09$ & $1.33 \pm 0.10$ & $1.16 \pm 0.10$ & $1.30 \pm 0.11$ & $\begin{array}{c}\mathrm{F}_{1,36}=0.35 \\
p=0.556 ; \\
\eta_{p}^{2}=0.010\end{array}$ & $\begin{array}{c}\mathbf{F}_{1,36}=437.07 \\
p< \\
\eta_{p}{ }^{2}=0.001 ;\end{array}$ & $\begin{array}{c}\mathrm{F}_{1,36}=0.60 \\
p=0.442 \\
\eta_{\mathrm{p}}^{2}=0.016\end{array}$ \\
\hline $\begin{array}{l}\text { Step width } \\
\quad(\mathrm{cm})\end{array}$ & $8.5 \pm 2.5$ & $8.2 \pm 2.7$ & $8.6 \pm 3.1$ & $8.8 \pm 4.1$ & $\begin{array}{c}\mathrm{F}_{1,36}=0.15 \\
p=0.703 \\
\eta_{p}{ }^{2}=0.004\end{array}$ & $\begin{array}{c}\mathrm{F}_{1,36}=0.01 ; \\
p=0.933 ; \\
\eta_{\mathrm{p}}^{2}=0.000\end{array}$ & $\begin{array}{c}\mathrm{F}_{1,36}=0.65 ; \\
p=0.425 ; \\
\eta_{\mathrm{p}}{ }^{2}=0.018\end{array}$ \\
\hline $\begin{array}{c}\text { Double } \\
\text { support } \\
\text { duration (s) }\end{array}$ & $0.17 \pm 0.02$ & $0.14 \pm 0.02$ & $0.17 \pm 0.02$ & $0.14 \pm 0.02$ & $\begin{array}{c}\mathrm{F}_{1,36}=0.01 ; \\
p=0.939 \\
\eta_{p}^{2}=0.000\end{array}$ & $\begin{array}{c}\mathrm{F}_{1,36}=374.77 \\
p<0.001 ; \\
\eta_{p}{ }^{2}=0.912 *\end{array}$ & $\begin{array}{c}\mathrm{F}_{1,36}=0.99 \\
p=0.755 \\
\eta_{p}^{2}=0.003\end{array}$ \\
\hline $\begin{array}{c}\text { Anterior } \\
\text { COM-COP IA } \\
\left(^{\circ}\right)\end{array}$ & $9.5 \pm 1.1$ & $11.5 \pm 1.2$ & $8.8 \pm 1.2$ & $10.7 \pm 1.3$ & $\begin{array}{c}\mathrm{F}_{1,36}=3.65 \\
p=0.064 \\
\eta_{\mathrm{p}}^{2}=0.092\end{array}$ & $\begin{array}{c}\mathrm{F}_{1,36}=387.14 \\
p<0.001 \\
\eta_{p}^{2}=0.915 *\end{array}$ & $\begin{array}{c}\mathrm{F}_{1,36}=0.00 \\
p=0.968 \\
\eta_{p}^{2}=0.000\end{array}$ \\
\hline $\begin{array}{c}\text { Posterior } \\
\text { COM-COP IA } \\
\left(^{\circ}\right)\end{array}$ & $6.7 \pm 0.8$ & $7.7 \pm 1.1$ & $7.0 \pm 1.0$ & $7.8 \pm 1.1$ & $\begin{array}{c}\mathrm{F}_{1,36}=0.38 \\
p=0.543 \\
\eta_{\mathrm{p}}^{2}=0.010\end{array}$ & $\begin{array}{c}\mathbf{F}_{1,36}=108.59 \\
p<0.001 \\
\eta_{p}^{2}=0.751 *\end{array}$ & $\begin{array}{c}\mathrm{F}_{1,36}=1.06 \\
p=0.311 ; \\
\eta_{\mathrm{p}}^{2}=0.028\end{array}$ \\
\hline $\begin{array}{l}\text { Medial COM- } \\
\text { COP IA }\left(^{\circ}\right)\end{array}$ & $2.9 \pm 0.9$ & $2.9 \pm 1.1$ & $3.3 \pm 1.1$ & $3.1 \pm 1.3$ & $\begin{array}{c}\mathrm{F}_{1,36}=0.89 \\
p=0.351 ; \\
\eta_{\mathrm{p}}^{2}=0.024\end{array}$ & $\begin{array}{c}\mathrm{F}_{1,36}=1.063 \\
p=0.309 \\
\eta_{\mathrm{p}}^{2}=0.029\end{array}$ & $\begin{array}{c}\mathrm{F}_{1,36}=0.44 \\
p=0.512 \\
\eta_{\mathrm{p}}^{2}=0.012\end{array}$ \\
\hline
\end{tabular}

\section{* statistical significance}




\section{Chapter IV}

\section{Discussion}

We hypothesized that older individuals with HV, when compared to healthy controls, would demonstrate greater deficits in dynamic balance for the faster walking speed condition but that dynamic balance deficits would not be observed at slower speeds. We, therefore, expected a group x speed interaction for the balance-related dependent variables. Our data did not support the hypothesis. Anterior, posterior, and medial IA and double support duration were not significantly different between groups for either speed condition (Table 2). We expected the group $\mathrm{x}$ speed interaction because dynamic balance challenge has been shown to increase with walking speed [19,20,46-49].

Consistent with previous research, our results showed that anterior and posterior IA increased significantly with increasing walking speed (Table 2). At faster speeds, the whole body COM moves more in the sagittal plane over the base of support [41], thus increasing the demand on dynamic balance to control the whole body COM with respect to the base of support. Also consistent with literature, our results further showed that double support duration decreased with increasing walking speed $[18,46]$ (Table 2). A decrease in duration of double support phase that occurs with faster speed presents a greater challenge to dynamic balance. This decrease in double support duration reflects a reduced amount of time to transfer weight from one leg to the other and control the more rapid movement of the COM over the new leading limb $[1,18,50]$. Overall, our sagittal plane IA data and duration of double support show that dynamic balance challenge did indeed increase with increasing walking speed.

For the frontal plane IA, we did not observe the anticipated decrease in peak angles with increased speed. Medial IA has previously been shown to decrease with increasing walking speed [19,20].

Interestingly, step width, which provides an indication of the base of support breadth in the frontal plane, was also not significantly affected by speed (Table 2). Generally, with an increase in walking speed, step width decreases [46]. These results are aligned with previous research which showed that frontal plane 
COM kinematics are related to step width [51]. COM-COP IA are computed from the whole body COM and the base of support (i.e., COP). An absence of speed effect on measures of the base of support such as step width could partially explain why changes were not observed in frontal plane COM-COP IA in this experiment. Perhaps the range of speeds selected in this study were not large enough to observe changes in frontal plane kinematics. The speed range in the current study was $1.0-1.3 \mathrm{~m} \cdot \mathrm{s}^{-1}$, whereas in previous research walking speeds ranged from $0.7-1.6 \mathrm{~m} \cdot \mathrm{s}^{-1}[19,20,46]$.

We did not observe dynamic balance deficits when comparing older adults with HV to healthy controls. When compared to healthy controls, older adults with balance deficits typically show increased peak medial IA and decreased peak anterior and posterior IA, which occur near the double stance phase of walking $[16,17,30]$. We did not observe such trends in our COM-COP IA results. Our data are comparable to previous results. When plotted over a gait cycle, our findings for peak COM-COP IAs are similar in profile but slightly lower in magnitude than those reported by Lee et al [16]. Although not consistent with our hypothesis, the lack of significant differences in dynamic balance between groups is consistent with previous findings on the balance of older adults with HV. Previous research that investigated differences in dynamic balance in older adults with HV and controls used less sensitive measures of dynamic balance, such as double support duration, and found no differences between groups $[12,13]$. Our data add to the literature on the effects of HV on balance control by examining differences in these groups using sensitive COM-COP IA measures of dynamic balance [16] and controlled, faster walking speeds. The observations from the current study and previous research cumulatively suggest that perhaps no differences in dynamic balance exist between older adults with HV and healthy older adults at comfortable speeds during continuous walking.

For the current study, we chose to control walking speed. Walking speed is known to be a confounding variable that independently influences spatiotemporal measures of gait and dynamic balance during walking [18-20]. We examined walking speeds of 1.0 and $1.3 \mathrm{~m} / \mathrm{s}$, as these speeds closely resemble self-selected comfortable walking speeds of older adults with (55-80 years) [10-12] and without 
HV (60-80 years) [36-38], respectively. Although the comparison of these speeds may be more representative of these populations' comfortable walking habits, it is possible that these speeds may not have been challenging or fast enough to uncover dynamic balance deficits. Future studies investigating dynamic balance in older adults with HV and healthy controls should consider increasing balance challenge by choosing faster speeds.

Participant inclusion and exclusion criteria for this study were highly rigorous. The older adults with HV who were recruited for this study had only the two more severe grades of the deformity. We elected to exclude mild forms of the deformity to elicit the most significant possible effect on dynamic balance $[5,9,10,52]$. In addition, these individuals had no obvious age-related comorbidities that would influence balance control. These highly rigorous criteria were intended to isolate the effects of HV from other aging-related comorbidities. A possible unintended consequence of our recruitment process was that the older adults with HV who met the recruitment criteria tended to be very physically active individuals (Table 1). Generally, older adults who are very physically active tend to have less deficits in dynamic balance during walking [53-55]. The possible confounding effect of physical activity may further explain why we did not observe differences in dynamic balance between groups. Future research should consider investigating dynamic balance in older adults with $\mathrm{HV}$ who are less active and have no age-related comorbidities.

In conclusion, healthy older adults with moderate-to-severe HV do not exhibit deficits in dynamic balance during walking across a range of comfortable speeds when compared to healthy older adults without HV. 


\section{Chapter V}

\section{Review of Literature}

\section{Introduction}

This review will broadly explore two main topics: hallux valgus (HV) and dynamic balance in older adults. Full comprehension of the proposed origins, treatments, and effects of HV is necessary to understand how this condition may impact factors of dynamic balance, particularly in walking. Dynamic balance is a complicated parameter, with a multitude of methods for calculation and interpretation that currently exist. This review will thoroughly appraise these methods of assessment and their accuracy in predicting dynamic balance in walking. Typical values expected of normal, healthy, subjects will also be reported and compared to those of older adults and those with unstable gait. Through this review, the author hopes to illuminate possible connections between HV and a decline in the dynamic balance of older adults.

\section{Hallux Valgus}

$\mathrm{HV}$ is a common foot deformity that can develop over the lifespan. The deformity is characterized by a deviation of the distal end of the great toe (i.e., hallux) away from the midline of the body [21]. Colloquially referred to as a bunion, HV is chronic and often progressive. Generally, a clinical diagnosis of $\mathrm{HV}$ is considered to be a deviation of 15 degrees or greater [4,56,57]. Most literature reports that HV incidence rates among mostly shod (i.e. shoe-wearing) populations fall between $20-45 \%$

$[3,4,56,58,59]$. These numbers are typically much higher in older adults beyond the age of 65 years, where incidence rates rise to $35-70 \%[23,58,60,61]$. HV is more prevalent in women than in men (35$60 \%$ ), particularly over the age of 60 years $[4,23,56,58,61,62]$. HV is usually a bilateral deformity, with only $17 \%$ of cases exhibiting the deformity in only one foot $[57,59]$. In the subsequent review, the causes, treatments, and effects of HV will be thoroughly explored. 


\section{Musculoskeletal and ligamentous contributions to hallux valgus}

Despite the large proportion of the population that suffers from this condition, a conclusive etiology of HV has yet to be identified. Some theories attribute its development to weakness in the muscles and ligaments surrounding the hallux. There is evidence that HV was accompanied by hypermobility in the first ray [57,63]. Subjects with HV have decreased plantarflexion and abduction strength at the hallux $[9,64]$. Pes planus, otherwise known as flat-footedness, is commonly observed in conjuction with HV $[3,58,65]$. Pes planus indicates increased ligament laxity at the forefoot, resulting in excess pronation [66]. Patients displaying both pes planus and HV may have inherent ligament weakness in the forefoot that contributes to the progression of HV. Indeed, changes in plantar pressures with HV indicate a medially-shifted loading pattern that is associated with overpronation [67]. However, since not everyone with HV also displays flat-footed characteristics, it is not likely that ligament weakness at the forefoot is the sole cause. Research on the role of muscular and ligamentous deficiencies in the development of $\mathrm{HV}$ has been limited. While it is likely from the evidence that certain muscles and ligaments may contribute to $\mathrm{HV}$, further examination is necessary to determine the significance of their contribution.

\section{Morphological differences associated with hallux valgus}

Many with HV claim the deformity is inherited from family members. This claim is supported by the literature, with more than $85 \%$ of people with HV self-reporting a family history [57]. Though scientists have yet to confirm this link conclusively, some research has illuminated inherited variation within the musculoskeletal structure of those with HV. HV patients typically have longer first metatarsal bones than their non-HV peers [57]. Radiographic assessments have shown that increased torsional angle at the first ray is linked to the development of $\mathrm{HV}$ [68]. A recent cadaveric study found that the accessory tendon of extensor hallucis longus muscle was more frequently found in conjunction with HV [69]. The 
presence of accessory tendons and altered bone structure may alter force vectors at the first ray, thus gradually contributing to the deformity over the lifespan. Simulation studies have shown that altered force vectors in the toes could lead to the development of progressive HV [70]. As with the theories on muscle and ligament weakness, however, these morphological differences are not prevalent enough to match the high prevalence of the deformity. The current evidence suggests that structural variation likely contributes, but cannot be confirmed as the sole cause.

\section{The contributions of footwear to the development of hallux valgus}

One of the more common theories on the etiology of HV is the contribution of footwear. Strong evidence suggests that long-term use of narrow, constrictive footwear such as high heels drastically increases the risk of developing HV $[4,62,70,71]$. This evidence may explain the higher incidence rates in female populations, who traditionally tend to wear narrower footwear and high heels. However, there is evidence that wearing shoes at all may increase risk. A study of a remote island community where many residents rarely wore shoes showed that $\mathrm{HV}$ incidence rates plummeted to $2 \%$ in traditionally-barefoot individuals [56]. It may be that wearing shoes, and especially those that are constrictive, exacerbates weaknesses and structural issues in the forefoot. Snijders and colleagues [70] proposed that the constriction of the toes by restrictive footwear may result in increased use of the first ray musculature through a deviant angle, possibly leading to the progressive development of the characteristic lateral deviation. A structural predisposition towards HV is likely exacerbated by footwear which inherently misaligns and detrains the musculature of the forefoot over the lifespan. While not significant on their own, these factors combined may explain the high prevalence rates of this deformity in shod populations. 


\section{Non-invasive treatment of hallux valgus}

Due to the nature of the proposed causes of $\mathrm{HV}$, prevention of the deformity is challenging. Treatment tends to focus on effective correction, though currently only a few methods of correction are well-supported. The nature of the musculature surrounding the first ray and the issues with force vectors makes re-strengthening the afflicted muscle groups difficult, though not impossible. Kim and colleagues [72] found that a toe-spreading training regimen lessened hallux angle and symptoms, as well as improved hallucis abductor muscle functioning. Corrective taping to straighten the hallux angle has been shown to affect certain aspects of balance in older patients with HV [73], and thus tends to be avoided. Still, no strengthening protocols have been shown to reverse the deviation. In milder cases, before patients reach the need for surgery, physicians recommend alterations to footwear selection or the addition of a custom-molded orthotic to current footwear [74]. Chadchavalpanichaya and colleagues [75] found that wearing a custom-molded toe separator overnight decreased hallux angle in subjects with moderate to severe HV. These forms of non-invasive treatment need further exploration to validate their effectiveness at reversing this condition. Though the study by Chadchavalpanichaya and colleagues showed an improvement in hallux angle in their treatment group, the change was minimal and still classified within the moderate to severe category. This study found that the control group hallux angle worsened while the treatment group improved over a 12-month period. This indicates that a custom orthotic, even worn at night, can potentially improve or at least halt the progression of HV. Currently, full reversal of the deformity is not possible outside of surgical measures.

\section{Surgical treatment of hallux valgus}

A vast number of surgeries are used to correct HV. Though several surgeries exist, no one procedure has been agreed upon as the gold standard for correcting HV [74,76]. Surgery becomes the primary correction of $\mathrm{HV}$ in cases where pain is debilitating and the hallux angle is severe enough to cause dysfunction. Most surgeries have fairly high success rates, but the rate of recurrence for nearly all 
of these procedures lies between 10 and $30 \%[57,77,78]$. As there is currently no widely accepted surgical treatment and the chances of reversing the condition outside of surgery are minimal, prevention of the deformity is critical. Further research is needed to explore recent developments in HV treatment and prevention.

\section{The grading of hallux valgus}

While treatment and prevention pose a challenge to physicians, the classifications of severity within this deformity remain relatively easy. HV is a visually apparent deformity. For medical professionals, this makes HV an easy affliction to diagnose. The current gold standard for HV classification is radiographic assessment to measure hallux angle and observe any torsional occurrences within the metatarsals [29]. Radiographs are cumbersome and costly however, and most patients will not elect for radiographic evaluation until symptoms become severe. Considering the prevalence of HV, a more cost-effective and easily accessible method of evaluation is warranted. This endeavor has been limited by the difficulty of accurately measuring exact hallux angle without the use of x-rays. Goniometric measurements have been invalidated in recent research due to their inability to reliably measure hallux angle [57,79].

\section{The Manchester Scale}

The most convenient and most commonly recommended tool used by clinicians and researchers is a scaling system that classifies the hallux angle into categories of severity, rather than measuring the exact angle. The Manchester Scale was first developed in 2001 by Garrow and colleagues [21] using standard, accepted photographs of hallux angle with increasing severity to classify the deformity (see Figure 1). While this style of classification does not provide an exact angle, it does provide a reliable classification of severity. It has been validated against radiographic assessment [29], and also against the 
American Orthopaedic Foot and Ankle Society Score index [28]. It is highly reliable for inter-rater assessment, and even reliable enough to be used without specific training [24]. The Manchester Scale is widely accepted as a reasonable alternative to radiographic assessment when exact hallux angle is not required.
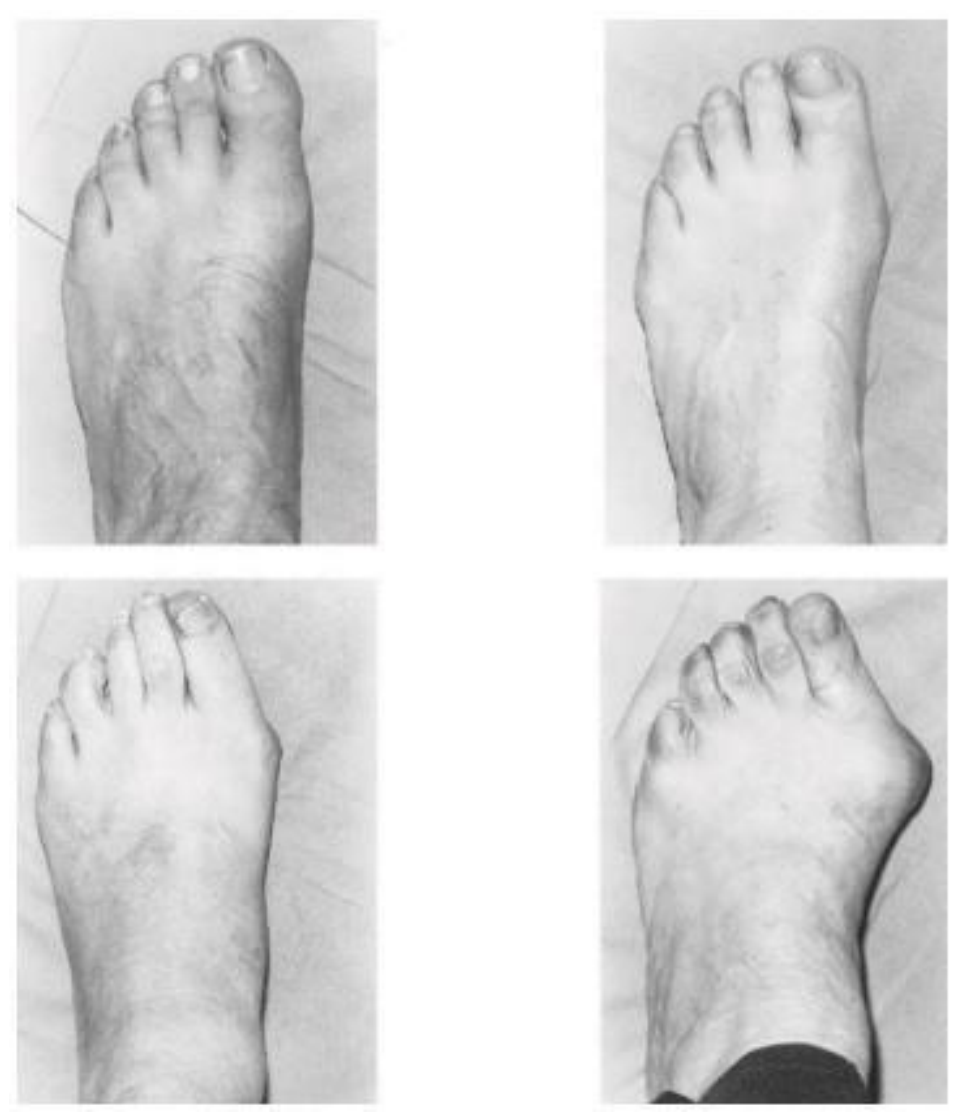

Figure 2. The Manchester Scale for the grading of HV [21]. Each image indicates a category of increasing severity: 0) no HV present, 1) mild HV, 2) moderate HV, and 3) severe HV.

\section{The impacts of hallux valgus on quality of life}

$\mathrm{HV}$ is affiliated with a broad range of symptoms and conditions that are not fully understood. The ones that clearly impact quality of life, such as pain or a loss of function, are often the ones that drive patients to seek medical attention for their deformity. The symptoms that impact quality of life usually do 
not surface until a patient reaches the moderate to severe classifications. Mild HV is not correlated with

pain or excessive dysfunction [80]. While milder forms of this deformity cause few issues, if any, HV is often progressive. The symptoms worsen as the deformity progresses, and virtually never recede on their own, often recurring even after intensive treatment measures are taken [81]. Many studies have shown that HV has a negative impact on quality of life. Patients with HV frequently complain of displeasure with the appearance of their feet and report difficulty selecting footwear [82]. HV has been associated increased hallux pain and decreased foot function [3,64], though this finding is more common in older adults and somewhat inconsistent. Other studies have shown that more severe HV is not always accompanied by debilitating foot pain [4]. HV is associated with arthritis in older adults however, which can produce pain symptoms separately. Kuryliszyn-Moskal and colleagues [83] found a correlation between increasing hallux angle and worsening osteoarthritis and rheumatoid arthritis. Some have suggested that HV may in fact worsen osteoarthritis, even in more proximal joints [84]. As mentioned earlier, HV produces a decline in toe strength, especially in severe HV $[6,9,64]$. HV also produces altered plantar pressure distributions [67]. Considering the progressive nature of $\mathrm{HV}$, it is possible that the decreased functioning and pain in the hallux with HV could precede larger deficits up the kinetic chain.

\section{The effect of hallux valgus on static balance}

Several studies have quantified the effects of HV on static stability and postural sway. Menz and colleagues [85] first linked foot deformities such as HV to declines in performance during tests of postural sway in older adults. Menz and his associates later found [22] that mediolateral sway is significantly impacted by severity of HV deformity in similar populations. These results have more recently been observed in younger demographics as well. Healthy adults between the ages of 20-76 years show increased mediolateral sway in subjects with HV during double-leg stance [64] and single-leg stance [9]. Patients with surgical correction for HV still show increased postural sway when compared with their non-HV peers [13]. HV is often accompanied by other issues such as arthritis and pain, as 
discussed earlier. It could be argued that these confounding variables may influence these results. However, a recent study showed that even mild HV angles in otherwise asymptomatic adults still results in a loss of mediolateral and overall stability in single-leg stance [7]. HV appears to have impacts on functional abilities in otherwise healthy adults. These deficits likely extend beyond static balance into areas of movement, such as walking.

\section{The effect of hallux valgus on spatiotemporal gait parameters}

Study of HV impact on spatiotemporal gait parameters has yielded relatively inconsistent results. Stride length and step length have been reported to be shorter in HV patients $[10,86]$. There is also evidence that stance time with HV subjects increases compared to controls [86,87]. Two studies [10,22] found that gait speed is decreased in older adults presenting with HV. Walking speed has been observed to decline in younger adults with HV as well [86]. Mickle et al. [12] found that walking speed was not affected in older adults with HV compared to controls. There are some minor inconsistencies on whether gait speed is affected by HV in the literature, though the majority appear to support a decline in walking speed with HV. Decreased gait speed, increased stance time, and shorter strides are typical characteristics that indicate an adoption of a more stable gait pattern to compensate for the decline in balance ability in older populations [1]. These alterations to spatiotemporal gait patterns in older HV subjects may suggest that a decline in dynamic balance during walking is present.

\section{The effect of hallux valgus on dynamic balance and fall risk}

Despite the indications for a decline in balance that exists within altered spatiotemporal gait parameters with $\mathrm{HV}$, only a few studies have examined performance in tests of dynamic balance in subjects with HV. Interestingly, these few have shown little indication of a decline in the dynamic balance of HV patients. A recent study observed no impact of HV on timed up-and-go performance nor in a step 
test [80]. Mickle and colleagues [12] found that gait variability during walking was not impacted by HV. Sadra and colleagues [13] found that trends of gait imbalance were not present patients with HV. However, some evidence that dynamic balance is affected still exits. Menz, Morris, and Lord [22] found that HV negatively impacted performance in sit-to-stand, alternating stepping, and coordinated stability performance. While the evidence suggests that HV has minimal, if unpredictable, impacts on dynamic balance, HV is known to be strongly associated with an increased risk for falls in older adults $[5,6,12,85]$. The gait of older adults was also found to be significantly less stable in older subjects presenting with moderate to severe HV, particularly on irregular surfaces [10]. It is unlikely that HV would affect static balance and fall risk so conclusively without also impacting dynamic balance, but no pattern has yet been discovered. The disconnect between these affiliated areas of literature within the study of HV suggests that an unknown mechanism behind the relationship between HV and dynamic balance that is not yet understood.

It should be noted that nearly all studies mentioned thus far examining dynamic balance in the gait of HV subjects did not control gait speed. To the author's knowledge, all studies thus far have examined HV subjects and controls who naturally walked at slower-than-normal speeds. Gait speed is widely known to have a large confounding effect on gait parameters, including measures of dynamic balance while walking $[18,88]$. Studies examining the impacts of HV on dynamic balance in walking tend to recruit older adult subjects, due to their inherent increased risk for falls. Older populations are known for slower self-selected walking speeds [89]. Older adults above the age of 60 years typically walk at a comfortable speed of 1.2-1.3 m/s, though this number declines as people age [90]. Small changes to gait speed produce large impacts on spatiotemporal gait parameters [18]. In all studies examining HV gait speed mentioned in this review, gait speed did not exceed 1.0-1.1 m/s, including those observing populations younger than 60 years $[10,12,86]$. The fact that all subjects, both HV and controls, in these studies walked slower than typical older adults indicates that some declines in gait velocity still exist. 
Future studies of the spatiotemporal gait parameters of adults with HV should consider controlling gait speed.

Furthermore, no study on dynamic balance in subjects with HV has measured dynamic balance using calculation of center of mass or its relationship with the base of support. The only study to have currently examined anything resembling center of mass movement was Sadra and colleagues [13]. The researchers examined center of mass mediolateral sway during steady state walking and found no relationship between HV subjects and controls. However, this finding may have been the product of not controlling for subject age and height or improper calculation of the center of mass. Another large limitation of that study was the exclusion of center of pressure interaction. The kinematics of the center of mass and its interaction with the base of support is highly predictive of gait instability and imbalance $[16,40,91]$. These concepts will be explored further in this review. In regards to HV however, further research with greater control for confounding variables is necessary to elucidate the true effects of $\mathrm{HV}$ on dynamic balance in walking.

\section{Dynamic Balance in Walking in Older Adults}

Dynamic balance is the ability to maintain posture without falling while experiencing perturbations from gravity, momentum, or other outside forces. Dynamic balance is particularly important to walking, where the body is in a constant state of imbalance. Without the ability to maintain balance dynamically, walking would be impossible. As humans age, dynamic balance declines and falls become more likely [92]. Falls are of great concern in older populations as they tend to be associated with increased morbidity rates and the likelihood of sustaining a traumatic injury [93]. Falls are also more likely in older adults exhibiting HV foot deformity [5,6]. However, the link between HV, fall risk, and dynamic balance during walking has not yet been identified. 


\section{Quantifying dynamic balance in walking}

Dynamic balance is complex and multifaceted. There are many different methods to quantify the variable ranging from simplistic spatiotemporal gait parameters to complicated center of mass calculations. There are currently five methods of quantifying dynamic balance during gait that are widely accepted, and these will be explored in the following subsections.

\section{Initial base of support}

Initial base of support is defined as the width between ankle joint centers upon heel strike [91]. It has also been referred to more generally in walking as step width [94], though initial base of support indicates an instantaneous value that occurs only at heel strike. Since dynamic balance is related to the ability to maintain the center of mass over a base of support [95], it seems reasonable that having a larger base of support might indicate greater stability. However, a number of studies have invalidated initial base of support as a mechanism for monitoring gait instability $[94,96]$.

\section{Double support duration}

Double-support duration (DSD) is defined as amount of time when both feet are in contact with the ground during a full gait cycle $[91,97,98]$. Longer amounts of time spent in double-support indicate the adoption of a safer, more stable pattern of walking, and usually indicate instability. Longer DSD values are associated with an increased risk for falls in older adults [99]. DSD decreases with vestibular rehabilitation in people suffering from balance issues affiliated with bilateral vestibular hypofunction [100]. However, the validity of DSD on its own may not accurately reflect the true presence of instability. DSD is often paired with other more sensitive measures of gait imbalance, such as alterations to center of mass trajectory [100]. 


\section{Center of mass velocity}

The complexity of dynamic balance during walking stems from the complexity inherent in the kinematics of the whole body center of mass (COM) during gait. One method for monitoring center of mass movement as an indicator of imbalance during gait is maximum and average anteroposterior (A-P) COM velocity. Average A-P COM velocity is defined as the change in COM position over the course of a gait cycle, while maximum A-P COM velocity is the greatest instantaneous change in COM displacement over time [91]. COM velocity in the forward direction is indicative of the ability to control momentum during gait, thus maintaining balance [101]. There is little consensus in the literature on how to interpret COM velocity, and many studies show mixed results [40,101]. COM position has been found to have a greater effect on balance than the velocity of the COM [102], which may suggest that A-P COM velocity is not as reliable of a method to assess balance capacity in walking. These findings imply that A-P COM velocity may not be as sensitive of an indicator of imbalance during walking as was previously thought.

\section{Center of mass-center of pressure separation}

The interactions between COM and center of pressure (COP) show far more promise in accurately reflecting dynamic balance capacities. Some have referred to the maximum moment arm as a highly sensitive indicator of balance in walking [91]. The horizontal separation of the COM from the COP indicates how far an individual is willing to allow their COM to displace from their base of support. This method of analyzing dynamic balance has been used extensively with great results $[15,34,40,91,103,104]$. COM-COP separation distances are versatile. They can be used to calculate separation in all three planes of motion [33]. They can be presented as peak values for a gait cycle $[40,103,104]$ or as instantaneous events of interest within a gait cycle, such as at heel strike and toe off [15,34]. Despite its sensitivity, versatility, and wide acceptance in the literature, COM-COP presents one major flaw. Subject height greatly impacts postural stabilization [95,105], yet COM-COP does not account for subject height. Without standardizing for intersubject height variability, COM-COP cannot accurately predict gait imbalance. 


\section{Center of mass-center of pressure inclination angles}

COM-COP inclination angles were developed as a method to account for intersubject height variability. Inclination angles (IA) were conceptualized and introduced by Lee and colleagues [16], as an angle that can be calculated using basic trigonometry using the height of the COM and the instantaneous COM-COP separation distance. By using COM-COP separation distance as part of the calculation of an IA, this methodology reaps the benefits and sensitivity of COM-COP separation while still accounting for the influence of subject height. COM-COP is widely accepted in the most recent literature as the most valid method for quantifying gait imbalances [19,20,31,32,42,106,107].

When measuring dynamic balance in walking, it is always best to validate findings by using more than one method to quantify the results. Utilizing both a COM-related variable and a spatiotemporal gait parameter (DSD) may mitigate any loss of accuracy in determining gait imbalances. For the purposes of this review, we will explore DSD and COM-COP inclination angles in the anterior-posterior and mediolateral directions as complementary measurements of dynamic balance during walking.

\section{Calculating COM-COP inclination angles}

As was previously stated, COM-COP inclination angles (IA) are currently the most broadly accepted method for determining dynamic balance, particularly in gait. Often, IA are calculated using basic trigonometry $[16,19]$. The simplest method is the original method, which was developed by Lee and colleagues [16] and is demonstrated below (see Figure 2). Per this method, IA are calculated as follows:

$$
\theta=\tan ^{-1}(d / h)
$$


where $\theta$ is the IA, $h$ is the instantaneous height of the COM, and $d$ is the corresponding horizontal distance between the COM and the COP.

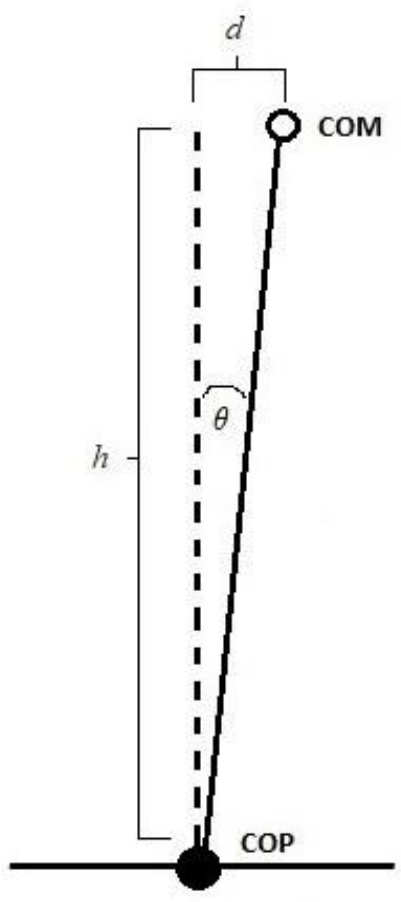

Figure 1. The calculation of the center of mass-center of pressure inclination angle uses the height of the COM $(h)$ and the horizontal separation of the center of mass and center of pressure $(d)$ to calculate the angle $(\theta)$, as shown above. This model can be applied to either the sagittal (anteriorposterior) or the frontal (mediolateral) planes.

Inclination angles are typically analyzed in the mediolateral (M-L) and anterior-posterior (A-P) directions. Typically, gait imbalance is associated with smaller peak A-P angles and greater peak M-L angles [16]. These peaks tend to occur at heel strike for the peak anterior COM-COP angle and at toe off for the peak posterior COM-COP angle [16], as weight is transferred from the trailing limb to the leading limb. Peak medial angles occur during double-support as well [16] The occurrence of these peaks at the start and end of the double-support phase indicate that the greatest area of interest for studying imbalance during gait is during the transfer of weight from one limb to the next.

COM can be calculated using a motion-sensing cameras and 39 reflective markers placed on a subject according to the VICON Plug-In Gait full body placement (see Figure 3) and two AMTI force plates. Segmental COMs are calculated and used to estimate whole body COM. The COP is recorded by 
each of the force plates when the foot is in contact with the plate. However, the area of interest occurs when one foot is on each force plate and the weight is distributed between both limbs. Therefore, COP must be calculated as a resultant $\mathrm{COP}$ using the following equation:

$$
C O P_{R}=C O P_{1} \frac{F_{Z 1}}{\left(F_{Z 2}+F_{Z 1}\right)}+\operatorname{COP}_{2} \frac{F_{Z 2}}{\left(F_{Z 1}+F_{Z 2}\right)}
$$

where $\mathrm{COP}_{\mathrm{R}}$ is the resultant $\mathrm{COP}, \mathrm{COP}_{1}$ and $\mathrm{COP}_{2}$ are each $\mathrm{COP}$ for the two respective force plates, and $\mathrm{F}_{\mathrm{Z} 1}$ and $\mathrm{F}_{\mathrm{Z} 2}$ are the vGRF from each respective force plate $[15,16,44]$. 


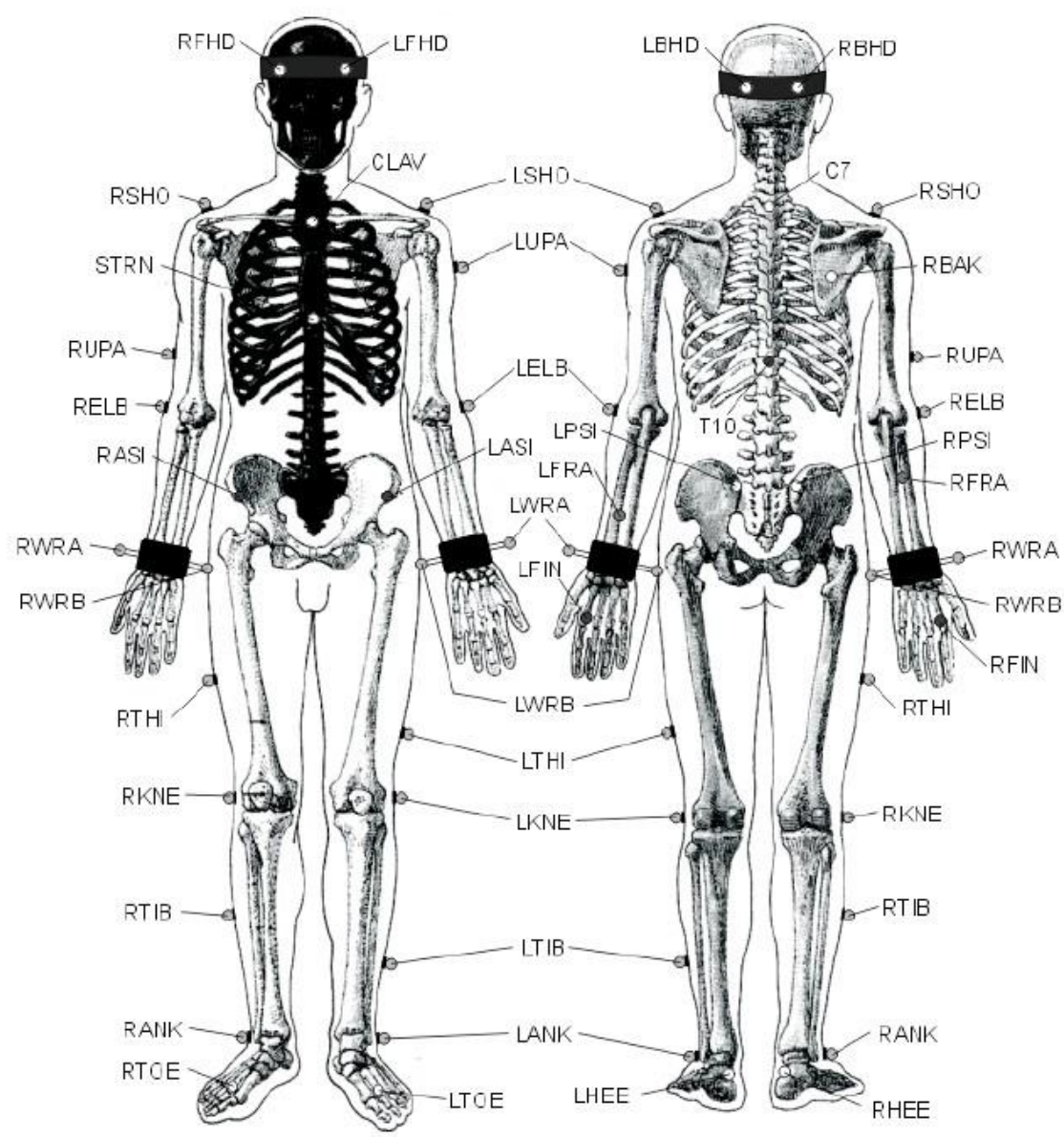

Figure 3. A diagram of the full-body marker placement as described by VICON Plug-In Gait (Centennial, CO, USA) as seen from an anterior (left) and posterior (right) view.

Acronyms: left/right forehead (LFHD/RFHD), left/right back of head (LBHD/RBHD), 7th cervical vertebrae (C7), 10th thoracic vertebrae (T10), clavicle (CLAV), sternum (STRN), right-side back (RBAK), left/right shoulder (LSHO/RSHO), left/right upper arm (LUPA/RUPA), left/right elbow (LELB/RELB), left/right forearm (LFRA/RFRA), left/right thumb-side wrist (LWRA/RWRA), left/right pinkie-side wrist (LWRB/RWRB), left/right 2nd metacarpal (LFIN/RFIN), left/right anterior superior iliac spine (LASI/RASI), left/right posterior superior iliac spine (LPSI/RPSI), left/right lateral mid-thigh (LTHI/RTHI), left/right lateral knee (LKNE/RKNE), left/right lateral mid-shank (LTIB/RTIB), left/right lateral malleolus of the fibula (LANK/RANK), left/right heel (LHEE/RHEE), and left/right 2nd metatarsal (LTOE/RTOE).

\section{Typical values for COM-COP inclination angles}

At preferred speeds, older adults with gait instability and a higher risk for falls tend to show an increase in medial or mediolateral (M-L) COM-COP peak IA while simultaneously showing a decrease in anterior and posterior (A-P) COM-COP peak IA (see Table 1). Fallers may not be willing to allow their COM to travel too far forward or back from their base of support, thus displaying a more cautious gait to prevent falls. This unwillingness to lean too far forward or back while walking may explain excess mediolateral movement, possibly resulting from a translation of momentum. The effects of $\mathrm{HV}$ on 
inclination angles have not yet been explored. Note that all studies listed in Table 1 did not control for gait speed, and that among those who reported gait speeds the older subjects with imbalance issues all walked at slower speeds. Gait speed has a large impact on gait parameters and COM movement during walking $[18,46]$. The possible consequences of not controlling for gait speed when studying dynamic balance in walking will be explored in a later section of this review.

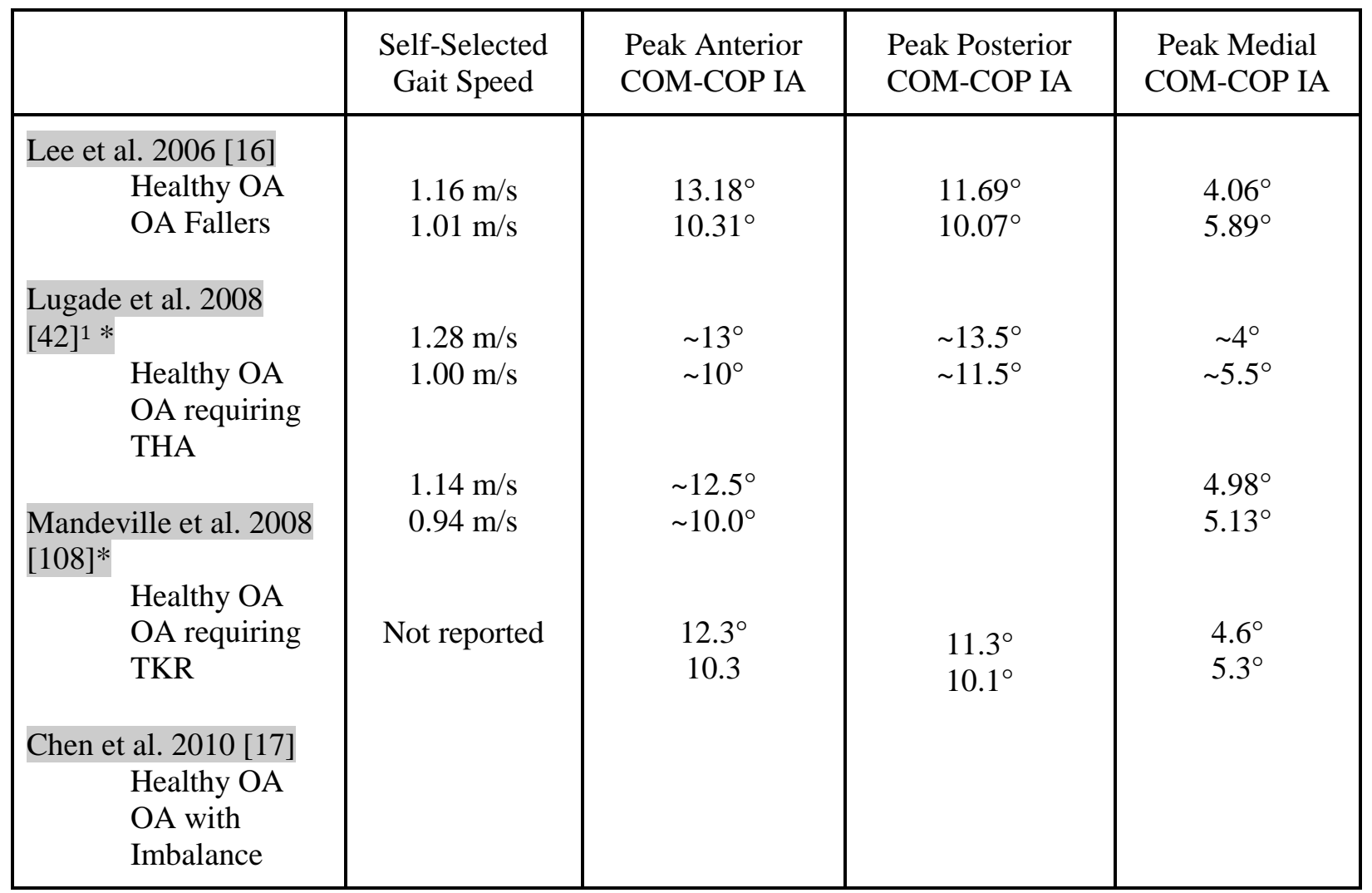

Table 3. A summary of results found by various studies examining peak A-P and M-L inclination angles when comparing healthy older adults against older adults with fall history, increased fall risk, or other conditions that may impact dynamic balance when walking. Some of those conditions included are subjects scheduled to receive a Total Hip Arthroplasty (THA) and Total Knee Replacement (TKR) surgery, which are a treatment for conditions associated with gait imbalance [109-111].

1indicates that exact inclination angles were not reported in the study, estimates are made from figures

*indicates that not all of the subjects in the study were within the ages of 60-80 years 
Due to its complexity, dynamic balance is most frequently calculated using more than one method $[91,97]$. For this reason, this next section will cover a complementary method of calculating dynamic balance alongside COM-COP IA: double support duration.

\section{Calculating double support duration}

Double support duration (DSD) is calculated as the amount of time when both feet are in contact with the ground. Often this value is easily normalized for intersubject variability by presenting it as a percentage of the gait cycle. Force plates are commonly used to measure DSD due to their sensitivity. Two force plates are necessary for quantifying DSD to distinguish between each foot's contact. Using force plates, DSD has been calculated as the time when both force plates' vertical ground reaction forces exceed negligible values $[19,31,107]$. This method pairs well with measures of COM-COP interaction, such as IA, because COP coordinates can be calculated from force plate data. Generally, commerciallyavailable force plate and motion capture software automatically calculate COP coordinates from forces and moments measured. DSD has been used previously to validate COM-COP IA as a measure of dynamic balance in walking $[19,31,107]$.

\section{Normal values for double support duration}

DSD usually only lasts for about $\sim 20 \%$ of the gait cycle, beginning at initial contact of the leading heel through pre-swing at the toe-off of the trailing leg [112]. Shorter DSD can indicate improvements in dynamic balance during walking [91,100]. Increased DSD is known to be affiliated with an increased risk for falls and gait disturbance $[99,113]$. Longer time spent in DSD may indicate the adoption of a more stable gait pattern to prevent falls and mitigate imbalance.

DSD increases drastically in older adults, showing DSD values ranging anywhere from $14 \%$ to $30 \%$ of the gait cycle $[47,98,99]$. Older adults with instability or increased fall risk tend to have these increased DSD values, rarely remaining in DSD for anything less than $20 \%$ of the gait cycle (see Table 
2). Larger DSD values suggest the adoption of a safer, more stable walking pattern that indicate imbalance while walking. Older adults are known for adopting safer, more stable patterns of walking, which may explain the trend for increased DSD in older populations. It is reasonable to expect this type of pattern to be exacerbated in older adults also suffering from conditions that challenge balance such as HV.

\section{Double support duration when hallux valgus is present}

Very few studies have examined double support as a measure of dynamic balance in patients with HV $[12,13]$. Though the results were not statistically significant, Sadra and colleagues [13] did find an increasing trend in DSD when comparing patients without HV against those with preoperative and postoperative HV. This finding may suggest that dynamic balance may be affected in those suffering from the HV deformity. Mickle and colleagues [12] conversely found minimal to no impact of HV of DSD. Further evidence is necessary to better understand the true effect of HV on DSD and balance while walking. 


\begin{tabular}{|c|c|c|}
\hline & $\begin{array}{c}\text { Self-Selected } \\
\text { Gait Speed }\end{array}$ & $\begin{array}{c}\text { Double Support } \\
\text { Duration }\end{array}$ \\
\hline Maki 1997 [98] & & $14.1 \% \mathrm{GC}$ \\
Healthy OA/no fear of falling & $0.79 \mathrm{~m} / \mathrm{s}$ & $18.2-19.8 \% \mathrm{GC}$ \\
OA Fallers/with fear of falling & $0.66-0.76 \mathrm{~m} / \mathrm{s}$ & \\
Verghese et al. 2009 [99] & & $26.60-30.0 \% \mathrm{GC}$ \\
Healthy OA & $0.95 \mathrm{~m} / \mathrm{s}$ & $+10 \% \mathrm{GC}$ \\
OA Fallers & $-0.1 \mathrm{~m} / \mathrm{s}$ & $22.4 \% \mathrm{GC}$ \\
Callisaya et al. 2011[114] & & $23.1-24.0 \% \mathrm{GC}$ \\
Healthy OA & $1.18 \mathrm{~m} / \mathrm{s}$ & \\
OA Fallers & $1.08-1.13 \mathrm{~m} / \mathrm{s}$ & $18.30 \% \mathrm{GC}$ \\
Sadra et al. 2013 [13]* & & $20.28 \% \mathrm{GC}$ \\
Healthy & $1.25 \mathrm{~m} / \mathrm{s}$ & $23.03 \% \mathrm{GC}$ \\
Preoperative HV & $1.25 \mathrm{~m} / \mathrm{s}$ & \\
Postoperative HV & $1.06 \mathrm{~m} / \mathrm{s}$ & $23.6 \% \mathrm{GC}$ \\
Mickle et al. 2011 [12] & & $24.0 \% \mathrm{GC}$ \\
Healthy & $1.00 \mathrm{~m} / \mathrm{s}$ & \\
HV & $1.03 \mathrm{~m} / \mathrm{s}$ & \\
& & \\
\hline
\end{tabular}

Table 4. A summary of results found in various studies examining DSD as a percentage of the gait cycle (GC) among older adult populations, populations of older adults experiencing imbalance or elevated fall risk during walking, and populations of older adults with hallux valgus (HV).

*indicates that not all of the subjects in the study were within the ages of 60-80 years 1. The researchers reported smaller than normal values because they chose to define DSD using only heel and metatarsal contact with the ground, excluding the period of toe contact to remove possible motion artifact that may have been caused by dragging the toes

2. This study evaluated the risk factors associated with falls. The researchers found that a $10 \%$ increase in DSD from the values reported for Healthy OA would result in a statistically significant increase in fall risk. This finding is reflected and supported by other studies [98,114]. 


\section{The effect of walking speed on measures of dynamic balance}

As mentioned previously in this review, walking speed has a large impact on parameters of gait. It is well known that walking speed influences spatiotemporal parameters, such as double support duration. In healthy adult subjects, double support duration decreases as walking speed increases [18]. As seen in Table 2, slower walking speed are correlated with longer DSD, though these values may also be impacted by age and instability. Other studies have reported that DSD values are longer at slower speeds and shorter at faster speeds $[19,20]$. COM movement is also affected by walking speed. Mediolateral COM movement decreases as walking speed increases in healthy, young adult subjects, though mediolateral COM excursion is smallest at preferred walking speeds [46]. If COM excursion is affected by walking speed, it seems likely that COM-COP inclination angles could possibly be impacted as well. Recent evidence has found that peak A-P COM-COP IA increase with increasing walking speed while ML COM-COP IA decrease in younger adult subjects $[19,20]$. Considering this evidence, walking speed should be treated as a confounding variable when studying dynamic balance in walking.

There are counter-arguments that advocate for preferred walking speed. Preferred walking speed is more externally valid as it is more representative of an individual's natural gait pattern. However, considering the threat to the internal validity of any outcomes measured using preferred walking speed, it may be prudent to test both preferred and controlled speed to mitigate this issue when conducting research on walking imbalance. Controlled speed trials should be set at a speed most representative of the age group being studied. This can account for the effect of age on walking speed [115,116]. In this case, both controlled and preferred speed trials may result in very similar gait velocities for each subject as a result. Regardless, the inclusion of both a controlled and self-selected speed walking trial is essential to maintain both the internal and external validity of any study examining dynamic balance. 


\section{Conclusion}

From the literature, it can be concluded HV is a condition with varying degrees of effect on foot strength, sensation, and function. The condition is progressive and irreversible without extreme treatment measures, and as a result tends to be more prevalent in older populations. This is concerning considering that the implications that HV has a detrimental effect on balance, both in standing and potentially also in walking. Balance is a key area of interest for older populations, who are at an increased risk for falls and often suffer from the serious complications that result from such incidents. Balance is difficult to measure, but there is a sensitive method of analysis that has yet to be used to verify the effects of $\mathrm{HV}$ on dynamic balance in walking. From this review, it is apparent that there is a need for research examining dynamic balance in walking in older adults with HV using more sensitive techniques. 


\section{References}

[1] D.A. Winter, A.E. Patla, J.S. Frank, S.E. Walt, Biomechanical walking pattern changes in the fit and healthy elderly, Phys. Ther. 70 (1990) 340-347.

[2] L.Z. Rubenstein, Falls in older people: Epidemiology, risk factors and strategies for prevention, Age Ageing. 35 (2006) ii37-ii41. doi:10.1093/ageing/afl084.

[3] C. González-Martín, F. Alonso-Tajes, S. Pérez-García, M.T. Seoane-Pillado, S. Pértega-Díaz, E. Couceiro-Sánchez, R. Seijo-Bestilleiro, S. Pita-Fernández, Hallux valgus in a random population in Spain and its impact on quality of life and functionality, Rheumatol. Int. 37 (2017) 1899-1907. doi:10.1007/s00296-017-3817-z.

[4] A.B. Dufour, V.A. Casey, Y.M. Golightly, M.T. Hannan, Characteristics associated with hallux valgus in a population-based study of older adults: The Framingham Foot Study, Arthritis Care Res. (Hoboken). 66 (2014) 1880-1886. doi:10.1002/acr.22391.Characteristics.

[5] H.B. Menz, M.E. Morris, S.R. Lord, Foot and ankle risk factors for falls in older people: a prospective study, J. Gerontol. Med. Sci. 61A (2006) 866-870. doi:61/8/866 [pii].

[6] K.J. Mickle, B.J. Munro, S.R. Lord, H.B. Menz, J.R. Steele, Toe weakness and deformity increase the risk of falls in older people, Clin. Biomech. 24 (2009) 787-791. doi:10.1016/j.clinbiomech.2009.08.011.

[7] Ö. Çinar-Medeni, N. Atalay Guzel, S. Basar, Mild hallux valgus angle affects single-limb postural stability in asymptomatic subjects, J. Back Musculoskelet. Rehabil. 29 (2016) 117-121. doi:10.3233/BMR-150606.

[8] M.J. Spink, M.R. Fotoohabadi, E. Wee, K.D. Hill, S.R. Lord, H.B. Menz, Foot and ankle strength, range of motion, posture, and deformity are associated with balance and functional ability in older adults, Arch. Phys. Med. Rehabil. 92 (2011) 68-75. doi:10.1016/j.apmr.2010.09.024.

[9] S.E. Hurn, B. Vicenzino, M.D. Smith, Functional impairments characterizing mild, moderate, and severe hallux valgus, Arthritis Care Res. 67 (2015) 80-88. doi:10.1002/acr.22380.

[10] H. Menz, S. Lord, Gait instability in older people with hallux valgus, Foot Ankle Int. 26 (2005) 483-489. https://www.illiad.library.wwu.edu/illiad.dll?Action $=10 \&$ Form $=75 \&$ Value $=672614$ (accessed April 23, 2018).

[11] M. Khazzam, J.T. Long, R.M. Marks, G.F. Harris, Kinematic changes of the foot and ankle in patients with systemic rheumatoid arthritis and forefoot deformity, J. Orthop. Res. 25 (2007) 319329. doi:10.1002/jor.20312.

[12] K.J. Mickle, B.J. Munro, S.R. Lord, H.B. Menz, J.R. Steele, Gait, balance and plantar pressures in older people with toe deformities, Gait Posture. 34 (2011) 347-351. doi:10.1016/j.gaitpost.2011.05.023.

[13] S. Sadra, A. Fleischer, E. Klein, G.S. Grewal, J. Knight, L.S. Weil, L. Weil, B. Najafi, Hallux valgus surgery may produce early improvements in balance control, J. Am. Podiatr. Med. Assoc. 103 (2013) 489-497. doi:10.7547/1030489.

[14] D.A. Winter, Human balance and posture control during standing and walking, Gait Posture. 3 (1995) 193-214. doi:10.1016/0966-6362(96)82849-9.

[15] R.L. Wright, D.M. Peters, P.D. Robinson, T.N. Watt, M.A. Hollands, Older adults who have previously fallen due to a trip walk differently than those who have fallen due to a slip, Gait 
Posture. 41 (2015) 164-169. doi:10.1016/j.gaitpost.2014.09.025.

[16] H.J. Lee, L.S. Chou, Detection of gait instability using the center of mass and center of pressure inclination angles, Arch. Phys. Med. Rehabil. 87 (2006) 569-575. doi:10.1016/j.apmr.2005.11.033.

[17] C.J. Chen, L.S. Chou, Center of mass position relative to the ankle during walking: A clinically feasible detection method for gait imbalance, Gait Posture. 31 (2010) 391-393. doi:10.1016/j.gaitpost.2009.11.010.

[18] C. Kirtley, M.W. Whittle, R.J. Jefferson, Influence of walking speed on gait parameters, J. Biomed. Eng. 7 (1985) 282-288. doi:10.1016/0141-5425(85)90055-X.

[19] H.L. Lu, M.Y. Kuo, C.F. Chang, T.W. Lu, S.W. Hong, Effects of gait speed on the body's center of mass motion relative to the center of pressure during over-ground walking, Hum. Mov. Sci. 54 (2017) 354-362. doi:10.1016/j.humov.2017.06.004.

[20] H.-L. Lu, T.-W. Lu, H.-C. Lin, H.-J. Hsieh, W.P. Chan, Effects of belt speed on the body's center of mass motion relative to the center of pressure during treadmill walking, Gait Posture. 51 (2016) 109-115. doi:10.1016/j.gaitpost.2016.09.030.

[21] A.P. Garrow, A. Papageorgiou, A.J. Silman, E. Thomas, M.I. V. Jayson, G.J. Macfarlane, The Grading of Hallux Valgus: Manchester Scale, J. Am. Podiatr. Med. Assoc. 91 (2001) 74-78.

[22] H.B. Menz, M.E. Morris, S.R. Lord, Foot and ankle characteristics associated with impaired balance and functional ability in older people, Journals Gerontol. - Ser. A Biol. Sci. Med. Sci. 60 (2005) 1546-1552. doi:10.1093/gerona/60.12.1546.

[23] E. Roddy, W. Zhang, M. Doherty, Prevalence and associations of hallux valgus in a primary care population, Arthritis Care Res. 59 (2008) 857-862. doi:10.1002/art.23709.

[24] H.B. Menz, M.R. Fotoohabadi, E. Wee, M.J. Spink, Validity of self-assessment of hallux valgus using the Manchester scale, BMC Musculoskelet. Disord. 11 (2010) 1-6. doi:10.1186/1471-2474$11-215$.

[25] K. Deschamps, I. Birch, K. Desloovere, G.A. Matricali, The impact of hallux valgus on foot kinematics: A cross-sectional, comparative study, Gait Posture. 32 (2010) 102-106. doi:10.1016/j.gaitpost.2010.03.017.

[26] S. Nix, T. Russell, B. Vicenzino, M. Smith, Validity and reliability of hallux valgus angle measured on digital photographs, J. Orthop. Sport. Phys. Ther. 42 (2012) 642-648. doi:10.2519/jospt.2012.3841.

[27] M.J. Park, Y.C. Ko, J.W. Huh, S.H. Park, T. hong Park, J. hyung Park, Validation of the Korean version of the Manchester-Oxford Foot Questionnaire in patients with Hallux Valgus, J. Foot Ankle Surg. 56 (2017) 252-254. doi:10.1053/j.jfas.2016.11.013.

[28] K. Iliou, G. Paraskevas, P. Kanavaros, A. Barbouti, A. Vrettakos, C. Gekas, P. Kitsoulis, Correlation between Manchester Grading Scale and American Orthopaedic Foot and Ankle Society Score in patients with hallux valgus, Med. Princ. Pract. 25 (2016) 21-24. doi:10.1159/000440809.

[29] H.B. Menz, S.E. Munteanu, Radiographic validation of the Manchester scale for the classification of hallux valgus deformity, Rheumatology. 44 (2005) 1061-1066.

doi:10.1093/rheumatology/keh687. 
[30] W.C. Hsu, T.M. Wang, M.W. Liu, C.F. Chang, H.L. Chen, T.W. Lu, Control of body's center of mass motion during level walking and obstacle-crossing in older patients with knee osteoarthritis, J. Mech. 26 (2010) 229-237. doi:10.1017/S1727719100003087.

[31] S.W. Hong, T.H. Leu, T.M. Wang, J. Da Li, W.P. Ho, T.W. Lu, Control of body's center of mass motion relative to center of pressure during uphill walking in the elderly, Gait Posture. 42 (2015) 523-528. doi:10.1016/j.gaitpost.2015.08.007.

[32] H.L. Chien, T.W. Lu, M.W. Liu, Control of the motion of the body's center of mass in relation to the center of pressure during high-heeled gait, Gait Posture. 38 (2013) 391-396.

doi:10.1016/j.gaitpost.2012.12.015.

[33] N.D. Reeves, M. Spanjaard, A.A. Mohagheghi, V. Baltzopoulos, C.N. Maganaris, Influence of light handrail use on the biomechanics of stair negotiation in old age, Gait Posture. 28 (2008) 327336. doi:10.1016/j.gaitpost.2008.01.014.

[34] E.L. Stegemoller, T.A. Buckley, C. Pitsikoulis, E. Barthelemy, R. Roemmich, C.J. Hass, Postural instability and gait impairment during obstacle crossing in parkinson's disease, Arch. Phys. Med. Rehabil. 93 (2012) 703-709. doi:10.1016/j.apmr.2011.11.004.

[35] C.J. Hass, D.E. Waddell, R.P. Fleming, J.L. Juncos, R.J. Gregor, Gait initiation and dynamic balance control in Parkinson's disease, Arch. Phys. Med. Rehabil. 86 (2005) 2172-2176. doi:10.1016/j.apmr.2005.05.013.

[36] T. Kimura, H. Kobayashi, E. Nakayama, M. Hanaoka, Effects of aging on gait patterns in the healthy elderly, Anthropol. Sci. 115 (2007) 67-72. doi:10.1537/ase.060309.

[37] E. Watelain, F. Barbier, P. Allard, A. Thevenon, J.-C. Angue, Gait pattern classification of healthy elderly men based on biomechanical data, Arch. Phys. Med. Rehabil. 81 (2000) 579-586.

[38] F. Prince, H. Corriveau, R. Hebert, A. Winter, Gait in the elderly, Gait Posture. 5 (1997) 128-135.

[39] H.H. Buddhadev, P.E. Martin, Effects of age and physical activity status on redistribution of joint work during walking, Gait Posture. 50 (2016) 131-136. doi:10.1016/j.gaitpost.2016.08.034.

[40] M.E. Hahn, L.S. Chou, Age-related reduction in sagittal plane center of mass motion during obstacle crossing, J. Biomech. 37 (2004) 837-844. doi:10.1016/j.jbiomech.2003.11.010.

[41] V. Lugade, V. Lin, L.S. Chou, Center of mass and base of support interaction during gait, Gait Posture. 33 (2011) 406-411. doi:10.1016/j.gaitpost.2010.12.013.

[42] V. Lugade, V. Klausmeier, B. Jewett, D. Collis, L.S. Chou, Short-term recovery of balance control after total hip arthroplasty, Clin. Orthop. Relat. Res. 466 (2008) 3051-3058. doi:10.1007/s11999008-0488-9.

[43] W.T. Dempster, G.R.L. CGaughran, Properties of body segnments base on size and weight, Am. J. Anat. 120 (1889) 33-54.

[44] Y. Jian, D. Winter, M. Ishac, L. Gilchrist, Trajectory of the body COG and COP during initiation and termination of gait, Gait Posture. 1 (1993) 9-22. doi:10.1016/0966-6362(93)90038-3.

[45] W. Vincent, Statistics in Kinesiology, 2nd ed., Human Kinetics Publishers Inc., Champaign, IL, 1999.

[46] M.S. Orendurff, A.D. Segal, G.K. Klute, J.S. Berge, E.S. Rohr, N.J. Kadel, The effect of walking speed on center of mass displacement., J. Rehabil. Res. Dev. 41 (2004) 829-834.

doi:10.1682/JRRD.2003.10.0150. 
[47] N. Shkuratova, M.E. Morris, F. Huxham, Effects of age on balance control during walking, Arch. Phys. Med. Rehabil. 85 (2004) 582-588. doi:10.1016/j.apmr.2003.06.021.

[48] Y. Gimmon, R. Riemer, H. Rashed, A. Shapiro, R. Debi, I. Kurz, I. Melzer, Age-related differences in pelvic and trunk motion and gait adaptability at different walking speeds, J. Electromyogr. Kinesiol. 25 (2015) 791-799. doi:10.1016/j.jelekin.2015.05.003.

[49] P.G. Adamczyk, A.D. Kuo, Redirection of center-of-mass velocity during the step-to-step transition of human walking, J. Exp. Biol. 212 (2009) 2668-2678. doi:10.1242/jeb.027581.

[50] M.S. Orendurff, G.C. Bernatz, J.A. Schoen, G.K. Klute, Kinetic mechanisms to alter walking speed, Gait Posture. 27 (2008) 603-610. doi:10.1016/j.gaitpost.2007.08.004.

[51] C.P. Hurt, N. Rosenblatt, J.R. Crenshaw, M.D. Grabiner, Variation in trunk kinematics influences variation in step width during treadmill walking by older and younger adults, Gait Posture. 31 (2010) 461-464. doi:10.1016/J.GAITPOST.2010.02.001.

[52] D.L. López, L.C. González, M.E.L. Iglesias, J.L.S. Canosa, D.R. Sanz, C.C. Lobo, R.B. Vallejo, Quality of Life Impact Related to Foot Health in a Sample of Older People with Hallux Valgus, Aging Dis. 7 (2016) 45. doi:10.14336/AD.2015.0914.

[53] S. Paulson, M. Gray, Parameters of gait among community-dwelling older adults, J. Geriatr. Phys. Ther. 38 (2015) 28-32. doi:10.1519/JPT.0000000000000018.

[54] R. Bulbulian, M.L. Hargan, The effect of activity history and current activity on static and dynamic postural balance in older adults, Physiol. Behav. 70 (2000) 319-325.

[55] B. Elsawy, K.E. Higgins, Physical activity guidelines for older adults., Am. Fam. Physician. 81 (2010) 55-9. http://www.ncbi.nlm.nih.gov/pubmed/20052963.

[56] I.B. Shine, Incidence of Hallux Valgus in a Partially Shoe-Wearing Community., Br. Med. J. 1 (1965) 1648-1650. doi:10.1136/bmj.1.5451.1648.

[57] M.J. Coughlin, C.P. Jones, Hallux valgus: demographics, etiology, and radiographic assessment, Foot Ankle Int. 28 (2007) 759-777. doi:10.3113/FAI.2007.0759.

[58] Y.M. Golightly, M.T. Hannan, A.B. Dufour, J.B. Renner, J.M. Jordan, Factors associated with hallux valgus in a community-based cross-sectional study of adults with and without osteoarthritis, Arthritis Care Res. 67 (2015) 791-798. doi:10.1002/acr.22517.

[59] J. Hughes, P. Clark, L. Klenerman, The importance of the toes in walking., J. Bone Jt. Surgery. Br. Vol. 72 (1990) 245-251. https://online.boneandjoint.org.uk/doi/pdf/10.1302/0301620X.72B2.2312564 (accessed February 26, 2018).

[60] G. Scott, H.B. Menz, L. Newcombe, Age-related differences in foot structure and function, Gait Posture. 26 (2007) 68-75. doi:10.1016/j.gaitpost.2006.07.009.

[61] J.E. Dunn, C.L. Link, D.T. Felson, M.G. Crincoli, J.J. Keysor, J.B. McKinlay, Prevalence of Food and Ankle Conditions in a Multiethnic Community Sample of Older Adults, Am. J. Epidemiol. 159 (2004) 491-498. doi:10.1093/aje/kwh071.

[62] U.S.D.T. Nguyen, H.J. Hillstrom, W. Li, A.B. Dufour, D.P. Kiel, E. Procter-Gray, M.M. Gagnon, M.T. Hannan, Factors associated with hallux valgus in a population-based study of older women and men: the MOBILIZE Boston Study, Osteoarthr. Cartil. 18 (2010) 41-46. doi:10.1016/j.joca.2009.07.008.

[63] T. Kimura, M. Kubota, T. Taguchi, N. Suzuki, A. Hattori, K. Marumo, Evaluation of first-ray 
mobility in patients with hallux valgus using weight-bearing CT and a 3-D analysis system a comparison with normal feet, J. Bone Jt. Surg. - Am. Vol. 99 (2017) 247-255.

doi:10.2106/JBJS.16.00542.

[64] S.E. Nix, B.T. Vicenzino, M.D. Smith, Foot pain and functional limitation in healthy adults with hallux valgus: A cross-sectional study, BMC Musculoskelet. Disord. 13 (2012) 1-10. doi:10.1186/1471-2474-13-197.

[65] V. Kalen, A. Brecher, Relationship between adolescent bunions and flatfeet, Foot Ankle Int. 8 (1988) 331-336. doi:10.1177/107110078800800609.

[66] a H. Franco, Pes cavus and pes planus. Analyses and treatment., Phys. Ther. 67 (1987) 688-694. doi:10.1093/ptj/67.5.688.

[67] A. Martínez-Nova, J.C. Cuevas-García, R. Sánchez-Rodríguez, J. Pascual-Huerta, E. SánchezBarrado, Study of plantar pressure patterns by means of instrumented insoles in subjects with hallux valgus, Rev. Española Cirugía Ortopédica y Traumatol. (English Ed. 52 (2008) 94-98. doi:10.1016/S1988-8856(08)70076-2.

[68] T. Ota, T. Nagura, T. Kokubo, M. Kitashiro, N. Ogihara, K. Takeshima, H. Seki, Y. Suda, M. Matsumoto, M. Nakamura, Etiological factors in hallux valgus, a three-dimensional analysis of the first metatarsal, J. Foot Ankle Res. 10 (2017) 1-6. doi:10.1186/s13047-017-0226-1.

[69] K. Natsis, G.A. Konstantinidis, P.D. Symeonidis, T. Totlis, N. Anastasopoulos, P. Stavrou, The accessory tendon of extensor hallucis longus muscle and its correlation to hallux valgus deformity: a cadaveric study, Surg. Radiol. Anat. 39 (2017) 1343-1347. doi:10.1007/s00276-017-1881-4.

[70] C.J. Snijders, J.G.N. Snijder, M.M.G.M. Philippens, Biomechanics of Hallux Valgus and Spread Foot, Foot Ankle Int. 7 (1986) 26-39. doi:10.1177/107110078600700106.

[71] T. Kato, S. Watanabe, The etiology of hallux valgus in Japan., Clin. Orthop. Relat. Res. 157 (1981) 78-81. http://www.ncbi.nlm.nih.gov/pubmed/7249466.

[72] M.-H. Kim, C.-H. Yi, J.-H. Weon, H.-S. Cynn, D.-Y. Jung, O.-Y. Kwon, Effect of toe-spread-out exercise on hallux valgus angle and cross-sectional area of abductor hallucis muscle in subjects with hallux valgus, J. Phys. Ther. Sci. 27 (2015) 1019-1022. doi:10.1589/jpts.27.1019.

[73] G. Gur, O. Ozkal, B. Dilek, S. Aksoy, N. Bek, Y. Yakut, Effects of Corrective Taping on Balance and Gait in Patients With Hallux Valgus, Foot Ankle Int. 38 (2017) 532-540. doi:10.1177/1071100716683347.

[74] L. Fraissler, C. Konrads, M. Hoberg, M. Rudert, M. Walcher, Treatment of hallux valgus deformity, EFORT Open Rev. 1 (2016) 295-302. doi:10.1302/2058-5241.1.000005.

[75] N. Chadchavalpanichaya, V. Prakotmongkol, N. Polhan, P. Rayothee, S. Seng-Iad, Effectiveness of the custom-mold room temperature vulcanizing silicone toe separator on hallux valgus: A prospective, randomized single-blinded controlled trial, Prosthet. Orthot. Int. (2017) 1-8. doi:10.1177/0309364617698518.

[76] J. Klugarova, V. Hood, F. Bath-Hextall, M. Klugar, J. Mareckova, Z. Kelnarova, Effectiveness of surgery for adults with hallux valgus deformity, JBI Database Syst. Rev. Implement. Reports. 15 (2017) 1671-1710. doi:10.11124/JBISRIR-2017-003422.

[77] R. Okuda, M. Kinoshita, T. Yasuda, T. Jotoku, H. Shima, M. Takamura, Hallux valgus angle as a predictor of recurrence following proximal metatarsal osteotomy, J. Orthop. Sci. 16 (2011) 760764. doi:10.1007/s00776-011-0136-1. 
[78] M.E. Easley, H.-J. Trnka, Current Concepts Review: Hallux Valgus Part II: Operative Treatment, Foot Ankle Int. 28 (2007) 748-758. doi:10.3113/FAI.2007.0748.

[79] D.C. Farber, J.K. DeOrio, M.W. Steel, Goniometric versus computerized angle measurement in assessing hallux valgus, Foot Ankle Int. 26 (2005) 234-238. doi:10.1177/107110070502600309.

[80] Y. Yoshimoto, Y. Oyama, M. Tanaka, Toe functions have little effect on dynamic balance ability in elderly people, J. Phys. Ther. Sci. 29 (2017) 158-162. doi:10.1589/jpts.29.158.

[81] X. Crevoisier, M. Assal, K. Stanekova, Hallux valgus, ankle osteoarthrosis and adult acquired flatfoot deformity: a review of three common foot and ankle pathologies and their treatments, EFORT Open Rev. 1 (2016) 58-64. doi:10.1302/2058-5241.1.000015.

[82] S. Nix yz, B. Vicenzino, N. Collins xk, Characteristics of foot structure and footwear associated with hallux valgus: a systematic review, Osteoarthr. Cartil. 20 (2012) 1059-1074. doi:10.1016/j.joca.2012.06.007.

[83] A. Kuryliszyn-Moskal, K. Kaniewska, Z. Dziecioł-Anikiej, P.A. Klimiuk, Evaluation of foot static disturbances in patients with rheumatic diseases, Reumatologia. 55 (2017) 73-78. doi:10.5114/reum.2017.67601.

[84] H. Guler, S. Karazincir, A.D. Turhanoglu, G. Sahin, A. Balci, C. Ozer, Effect of coexisting foot deformity on disability in women with knee osteoarthritis, J Am Pod. Med Assoc. 99 (2009) 23 27. doi:10.7547/0980023.

[85] H.B. Menz, B. Pod, S.R. Lord, The contribution of foot problems to mobility impairment and falls in community-dwelling older people, JAGS. 49 (2001) 1651-1656. https://onlinelibrary-wileycom.ezproxy.library.wwu.edu/doi/pdf/10.1111/j.1532-5415.2001.49275.x (accessed April 23, 2018).

[86] K. Canseco, J. Long, T. Smedberg, S. Tarima, R.M. Marks, G.F. Harris, Multisegmental foot and ankle motion analysis after hallux valgus surgery, Foot Ankle Int. 33 (2012) 141-147. doi:10.3113/FAI.2012.0141.

[87] B. Jeong, S. Kim, J. Son, Y. Kim, 3D analysis of the metatarsophalangeal joint in normal group and Hallux valgus patients during walking using a four-segment foot model, Int. J. Precis. Eng. Manuf. 15 (2014) 299-303. doi:10.1007/s12541-014-0338-5.

[88] K. Jordan, J.H. Challis, K.M. Newell, Walking speed influences on gait cycle variability, Gait Posture. 26 (2007) 128-134. doi:10.1016/j.gaitpost.2006.08.010.

[89] S. Studenski, S. Perera, K. Patel, Gait speed and survival in older adults, J. Am. Med. Assoc. 305 (2011) 50-58. doi:10.1001/jama.2010.1923.Gait.

[90] R.W. Bohannon, Comfortable and maximum walking speed of adults aged 20-79 years: Reference values and determinants, Age Ageing. 26 (1997) 15-19. doi:10.1093/ageing/26.1.15.

[91] C.A. McGibbon, D.E. Krebs, D.M. Scarborough, Rehabilitation effects on compensatory gait mechanics in people with arthritis and strength impairment, Arthritis Rheum. 49 (2003) 248-254. doi:10.1002/art.11005.

[92] T.W. O’Neill, J. Varlow, A.J. Silman, J. Reeve, D.M. Reid, C. Todd, A.D. Woolf, Age and sex influences on fall characteristics, Ann. Rheum. Dis. 53 (1994) 773-775. doi:10.1136/ard.53.11.773.

[93] M.D. Grabiner, M.J. Pavol, T.M. Owings, Can fall-related hip fractures be prevented by 
characterizing the biomechanical mechanisms of failed recovery?, Endocrine. 17 (2002) 15-20. doi:10.1385/ENDO:17:1:15.

[94] B. Seidel, D.E. Krebs, Base of support is not wider in chronic ataxic and unsteady patients, J. Rehabil. Med. 34 (2002) 288-292. doi:10.1080/165019702760390392.

[95] W. Berger, M. Trippel, M. Discher, V. Dietz, Influence of subjects' height on the stabilization of posture, Acta Otolaryngol. 112 (1992) 22-30.

[96] D.E. Krebs, D. Goldvasser, J.D. Lockert, L.G. Portney, K.M. Gill-Body, Is base of support greater in unsteady gait?, Phys. Ther. 82 (2002) 138-147. doi:10.1093/ptj/82.2.138.

[97] C.A. Tucker, J. Ramirez, D.E. Krebs, P.O. Riley, Center of gravity dynamic stability in normal and vestibulopathic gait, Gait Posture. 8 (1998) 117-123. doi:10.1016/S0966-6362(98)00030-7.

[98] B.E. Maki, Gait changes in older adults: Predictors of falls or indicators of fear?, J. Am. Geriatr. Soc. 45 (1997) 313-320. doi:10.1111/j.1532-5415.1997.tb00946.x.

[99] J. Verghese, R. Holtzer, R.B. Lipton, C. Wang, Quantitative gait markers and incident fall risk in older adults, Journals Gerontol. - Ser. A Biol. Sci. Med. Sci. 64 (2009) 896-901. doi:10.1093/gerona/glp033.

[100] D.E. Krebs, K.M. Gill-Body, P.O. Riley, S.W. Parker, Double-blind, placebo-controlled trial of rehabilitation for bilateral vestibular hypofunction: Preliminary report, Otolaryngol. - Head Neck Surg. 109 (1993) 735-741. doi:10.1177/019459989310900417.

[101] M. Fujimoto, L.S. Chou, Sagittal plane momentum control during walking in elderly fallers, Gait Posture. 45 (2016) 121-126. doi:10.1016/j.gaitpost.2016.01.009.

[102] Y.-C. Pai, J. Patton, Center of mass velocity-position for balance control predictions, Phys. Ther. 30 (1997) 347-354. doi:10.1016/S0021-9290(96)00165-0.

[103] L.S. Chou, K.R. Kaufman, R.H. Brey, L.F. Draganich, Motion of the whole body's center of mass when stepping over obstacles of different heights, Gait Posture. 13 (2001) 17-26. doi:10.1016/S0966-6362(00)00087-4.

[104] L.S. Chou, K.R. Kaufman, A.E. Walker-Rabatin, R.H. Brey, J.R. Basford, Dynamic instability during obstacle crossing following traumatic brain injury, Gait Posture. 20 (2004) 245-254. doi:10.1016/j.gaitpost.2003.09.007.

[105] A. Alonso, N. Luna, L. Mochizuki, F. Barbieri, S. Santos, J. D’Andreia Greve, The influence of anthropometric factors on postural balance: the relationship between body composition and posturographic measurements in young adults, Clinics. 67 (2012) 1433-1441. doi:10.6061/clinics/2012(12)14.

[106] S.C. Huang, T.W. Lu, H.L. Chen, T.M. Wang, L.S. Chou, Age and height effects on the center of mass and center of pressure inclination angles during obstacle-crossing, Med. Eng. Phys. 30 (2008) 968-975. doi:10.1016/j.medengphy.2007.12.005.

[107] H.L. Chien, T.W. Lu, M.W. Liu, Effects of long-term wearing of high-heeled shoes on the control of the body's center of mass motion in relation to the center of pressure during walking, Gait Posture. 39 (2014) 1045-1050. doi:10.1016/j.gaitpost.2014.01.007.

[108] D. Mandeville, L.R. Osternig, L.S. Chou, The effect of total knee replacement surgery on gait stability, Gait Posture. 27 (2008) 103-109. doi:10.1016/j.gaitpost.2007.02.009.

[109] R.S. Hinman, K.L. Bennell, B.R. Metcalf, K.M. Crossley, Balance impairments in individuals 
with symptomatic knee osteoarthritis: a comparison with matched controls using clinical tests., Rheumatology (Oxford). 41 (2002) 1388-1394. https://academic.oup.com/rheumatology/articleabstract/41/12/1388/1783904 (accessed July 23, 2018).

[110] C.M. Arnold, R.A. Faulkner, The history of falls and the association of the timed up and go test to falls and near-falls in older adults with hip osteoarthritis, BMC Geriatr. 7 (2007). doi:10.1186/1471-2318-7-17.

[111] D.L. Sturnieks, A. Tiedemann, K. Chapman, B. Munro, S.M. Murray, S.R. Lord, Physiological risk factors for falls in older people with lower limb arthritis., J Rheumatol. 31 (2004) 2272-2279. https://s3.amazonaws.com/academia.edu.documents/45621658/Physiological_risk_factors_for_fall s_in_20160514-21778-

1ikdkqj.pdf?AWSAccessKeyId=AKIAIWOWYYGZ2Y53UL3A\&Expires=1532102637\&Signatu re $=0 \mathrm{IkH} \% 2 \mathrm{BuVSMX3YAEqWow2aOTTA8fY \% 3D \& response-content-disposition=inli} \mathrm{(accessed}$ July 20, 2018).

[112] J.M. Adams, K. Cerny, Observational Gait Analysis: A Visual Guide, SLACK Incorporated, Thorofare, NJ, 2018.

[113] H. Stolze, S. Klebe, G. Petersen, J. Raethjen, R. Wenzelburger, K. Witt, G. Deuschl, Typical features of cerebellar ataxic gait, J. Neurol. Neurosurg. Psychiatry. 73 (2002) 310-312. doi:10.1136/jnnp.73.3.310.

[114] M.L. Callisaya, L. Blizzard, M.D. Schmidt, K.L. Martin, J.L. Mcginley, L.M. Sanders, V.K. Srikanth, Gait, gait variability and the risk of multiple incident falls in older people: A populationbased study, Age Ageing. 40 (2011) 481-487. doi:10.1093/ageing/afr055.

[115] M.M. Samson, A. Crowe, P.L. de Vreede, J.A.G. Dessens, S.A. Duursma, H.J.J. Verhaar, Differences in gait parameters at a preferred walking speed in healthy subjects due to age, height, and body weight, Aging; Clin. Exp. Res. 13 (2001) 16-21.

[116] R.W. Bohannon, Population representative gait speed and its determinants, J. Geriatr. Phys. Ther. 31 (2008) 49-52. doi:10.1519/00139143-200831020-00002. 


\section{APPENDIX A}

\section{Western Washington University Informed Consent}

\section{The effects of bunions on walking balance in older adults at fixed speeds}

We are asking you to be in a research study. Participation is voluntary. The purpose of this form is to give you the information you will need to help you decide whether to participate. Please read the form carefully. You may ask questions about anything that is not clear. When we have answered all of your questions, you can decide if you want to be in the study or not. This process is called "informed consent."

Purpose and Benefit:

This research aims to examine the effects of bunions on balance during walking in older adults at fixed walking speeds. The effects of this common foot condition on balance in older adults are not fully understood. This study will increase our current understanding of how bunions impact balance during walking in older adults.

I understand that:

- To be eligible for this research, participants should be:

- between the ages of 60 and 85 years

- able to walk continuously for at least 10 minutes

- Participant is aware that the entirety of the testing session will be conducted in bare feet while wearing spandex clothing and reflective markers placed on the clothes and the skin.

- Participation in this research will involve the completion of 5 walking trials at two controlled walking speeds (2.2 and $2.9 \mathrm{mph}$ ) for a total of 10 trials. Participation will require approximately a 1-hour time commitment.

- Participant's feet will be visually examined to determine if bunions are present on the feet or not. • There are minimal risks from participation in this research. Participant may experience some mild fatigue from the walking trials.

- The participant understands that there are no potential direct benefits from participation in this study.

- Participation is completely voluntary. Participants are able to withdraw from this research at any time without penalty or loss of benefits to which they are otherwise entitled.

- All information is confidential. Participants will be given an ID number for this study, which will be used to label their data. The link between this ID number and the participant's name and other identifying information will be stored separately. Only the primary investigator and graduate researcher will have access to the data collected from this study.

- Participant signature on this form does not waive any legal rights of protection.

- A physical copy of this informed consent form will be provided to the participant upon arrival at the laboratory. 
This research is conducted by Carolyn Barbee under the supervision of Dr. Harsh Buddhadev. Any questions that you have regarding the study or your participation may be directed to Dr. Harsh Buddhadev at harsh.buddhadev@wwu.edu or to Carolyn Barbee at barbeec@wwu.edu.

If you have any questions about your participation or your rights as a research participant, you can contact the WWU Office of Research and Sponsored Programs (RSP) at compliance@wwu.edu or (360) 6502146. If during or after participation in this study you suffer from any adverse effects as a result of participation, please notify the researcher directing the study or the RSP.

By signing below you are saying that you have read this form, that you have had your questions answered, that you understand the tasks involved, and volunteer to take part in this research.

I have read the above description and agree to participation in this study.

Participant's Signature:

Date:

Participant's Printed Name: 
APPENDIX B: Gait \& Posture Format Guidelines

\section{GUIDE FOR AUTHORS}

\section{JOURNAL DESCRIPTION}

Gait and Posture publishes new and innovative basic and clinical research on all aspects of human movement, locomotion and balance.

The topics covered include: Techniques for the measurement of gait and posture, and the standardization of results presentation; Studies of normal and pathological gait; Treatment of gait and postural abnormalities; Biomechanical and theoretical approaches to gait and posture; Mathematical models of joint and muscle mechanics; Neurological and musculoskeletal function in gait and posture; The evolution of upright posture and bipedal locomotion; Adaptations of carrying loads, walking on uneven surfaces, climbing stairs, running and performing other movements. Spinal biomechanics only if they are directly related to gait and/or posture and are of general interest to our readers; The effect of aging and development on gait and posture; Psychological and cultural aspects of gait; Patient education.

Submission checklist

You can use this list to carry out a final check of your submission before you send it to the journal for review. Please check the relevant section in this Guide for Authors for more details.

Ensure that the following items are present:

One author has been designated as the corresponding author with contact details: E-mail address Full postal address

All necessary files have been uploaded:

Manuscript: Include 3-5 keywords Include a structured abstract (see below for format) All figures (include relevant captions) All tables (including titles, description, footnotes) Ensure all figure and table citations in the text match the files provided Indicate clearly if color should be used for any figures in print Graphical Abstracts / Highlights files (where applicable) Supplemental files (where applicable)

Further considerations Manuscript has been 'spell checked' and 'grammar checked' All references mentioned in the Reference List are cited in the text, and vice versa Permission has been obtained for use of copyrighted material from other sources (including the Internet) A competing interests statement is provided, even if the authors have no competing interests to declare Journal policies detailed in this guide have been reviewed Referee suggestions and contact details provided, Based on journal requirements For further information, visit our Support Center Support Center.

\section{BEFORE YOU BEGIN}

\section{Ethics in publishing}

Please see our information pages on Ethics in publishing and Ethical guidelines for journal publication.

\section{Declaration of interest}

All authors must disclose any financial and personal relationships with other people or organizations that could inappropriately influence (bias) their work. Examples of potential competing interests include employment, consultancies, stock ownership, honoraria, paid expert testimony, patent applications/registrations, and grants or other funding. Authors must disclose any interests in two places: 1. A summary declaration of interest statement in the title page file (if double-blind) or the manuscript file (if single-blind). If there are no interests to declare then please state this: 'Declarations of interest: none'. This summary statement will be ultimately published if the article is accepted. 2. Detailed disclosures as part of a separate Declaration of Interest form, which forms part of the journal's official records. It is important for potential interests to be declared in both places and that the information matches. More information.

\section{Submission declaration and verification}

Submission of an article implies that the work described has not been published previously (except in the form of an abstract, a published lecture or academic thesis, see 'Multiple, redundant or concurrent publication' for more information), that it is not under consideration for publication elsewhere, that its publication is approved by all authors and tacitly or explicitly by the responsible authorities where the work was carried out, and that, if accepted, it will not be published elsewhere in the same form, in 
English or in any other language, including electronically without the written consent of the copyrightholder. To verify originality, your article may be checked by the originality detection service Crossref Similarity Check.

Preprints

Please note that preprints can be shared anywhere at any time, in line with Elsevier's sharing policy. Sharing your preprints e.g. on a preprint server will not count as prior publication (see 'Multiple, redundant or concurrent publication' for more information).

\section{Use of inclusive language}

Inclusive language acknowledges diversity, conveys respect to all people, is sensitive to differences, and promotes equal opportunities. Articles should make no assumptions about the beliefs or commitments of any reader, should contain nothing which might imply that one individual is superior to another on the grounds of race, sex, culture or any other characteristic, and should use inclusive language throughout. Authors should ensure that writing is free from bias, for instance by using 'he or she', 'his/her' instead of 'he' or 'his', and by making use of job titles that are free of stereotyping (e.g. 'chairperson' instead of 'chairman' and 'flight attendant' instead of 'stewardess').

\section{Author contributions}

For transparency, we encourage authors to submit an author statement file outlining their individual contributions to the paper using the relevant CRediT roles: Conceptualization; Data curation; Formal analysis; Funding acquisition; Investigation; Methodology; Project administration; Resources; Software; Supervision; Validation; Visualization; Roles/Writing - original draft; Writing - review \& editing. Authorship statements should be formatted with the names of authors first and CRediT role(s) following. More details and an example

\section{Authorship}

All authors should have made substantial contributions to all of the following: (1) the conception and design of the study, or acquisition of data, or analysis and interpretation of data, (2) drafting the article or revising it critically for important intellectual content, (3) final approval of the version to be submitted.

\section{Changes to authorship}

Authors are expected to consider carefully the list and order of authors before submitting their manuscript and provide the definitive list of authors at the time of the original submission. Any addition, deletion or rearrangement of author names in the authorship list should be made only before the manuscript has been accepted and only if approved by the journal Editor. To request such a change, the Editor must receive the following from the corresponding author: (a) the reason for the change in author list and (b) written confirmation (e-mail, letter) from all authors that they agree with the addition, removal or rearrangement. In the case of addition or removal of authors, this includes confirmation from the author being added or removed.

Only in exceptional circumstances will the Editor consider the addition, deletion or rearrangement of authors after the manuscript has been accepted. While the Editor considers the request, publication of the manuscript will be suspended. If the manuscript has already been published in an online issue, any requests approved by the Editor will result in a corrigendum.

\section{Clinical trial results}

In line with the position of the International Committee of Medical Journal Editors, the journal will not consider results posted in the same clinical trials registry in which primary registration resides to be prior publication if the results posted are presented in the form of a brief structured (less than 500 words) abstract or table. However, divulging results in other circumstances (e.g., investors' meetings) is discouraged and may jeopardise consideration of the manuscript. Authors should fully disclose all posting in registries of results of the same or closely related work.

\section{Article transfer service}

This journal is part of our Article Transfer Service. This means that if the Editor feels your article is more suita ble in one of our other participating journals, then you may be asked to consider transferring the article to one of those. If you agree, your article will be transferred automatically on your behalf with no need to reformat. Please note that your article will be reviewed again by the new journal. More information. 


\section{Copyright}

Upon acceptance of an article, authors will be asked to complete a 'Journal Publishing Agreement' (see more information on this). An e-mail will be sent to the corresponding author confirming receipt of the manuscript together with a 'Journal Publishing Agreement' form or a link to the online version of this agreement.

Subscribers may reproduce tables of contents or prepare lists of articles including abstracts for internal circulation within their institutions. Permission of the Publisher is required for resale or distribution outside the institution and for all other derivative works, including compilations and translations. If excerpts from other copyrighted works are included, the author(s) must obtain written permission from the copyright owners and credit the source(s) in the article. Elsevier has preprinted forms for use by authors in these cases.

For gold open access articles: Upon acceptance of an article, authors will be asked to complete an 'Exclusive License Agreement' (more information). Permitted third party reuse of gold open access articles is determined by the author's choice of user license.

\section{Author rights}

As an author you (or your employer or institution) have certain rights to reuse your work. More information.

Elsevier supports responsible sharing

Find out how you can share your research published in Elsevier journals.

\section{Role of the funding source}

You are requested to identify who provided financial support for the conduct of the research and/or preparation of the article and to briefly describe the role of the sponsor(s), if any, in study design; in the collection, analysis and interpretation of data; in the writing of the report; and in the decision to submit the article for publication. If the funding source(s) had no such involvement then this should be stated.

\section{Funding body agreements and policies}

Elsevier has established a number of agreements with funding bodies which allow authors to comply with their funder's open access policies. Some funding bodies will reimburse the author for the gold open access publication fee. Details of existing agreements are available online.

After acceptance, open access papers will be published under a noncommercial license. For authors requiring a commercial CC BY license, you can apply after your manuscript is accepted for publication.

\section{Open access}

This journal offers authors a choice in publishing their research:

\section{Subscription}

- Articles are made available to subscribers as well as developing countries and patient groups through our universal access programs.

- No open access publication fee payable by authors.

- The Author is entitled to post the accepted manuscript in their institution's repository and make this public after an embargo period (known as green Open Access). The published journal article cannot be shared publicly, for example on ResearchGate or Academia.edu, to ensure the sustainability of peerreviewed research in journal publications. The embargo period for this journal can be found below.

\section{Gold open access}

- Articles are freely available to both subscribers and the wider public with permitted reuse.

- A gold open access publication fee is payable by authors or on their behalf, e.g. by their research funder or institution.

Regardless of how you choose to publish your article, the journal will apply the same peer review criteria and acceptance standards.

For gold open access articles, permitted third party (re)use is defined by the following Creative Commons user licenses: 
Creative Commons Attribution-NonCommercial-NoDerivs (CC BY-NC-ND)

For non-commercial purposes, lets others distribute and copy the article, and to include in a collective work (such as an anthology), as long as they credit the author(s) and provided they do not alter or modify the article.

The gold open access publication fee for this journal is USD 3500, excluding taxes. Learn more about Elsevier's pricing policy: https://www.elsevier.com/openaccesspricing.

Green open access

Authors can share their research in a variety of different ways and Elsevier has a number of green open access options available. We recommend authors see our open access page for further information. Authors can also self-archive their manuscripts immediately and enable public access from their institution's repository after an embargo period. This is the version that has been accepted for publication and which typically includes author-incorporated changes suggested during submission, peer review and in editor-author communications. Embargo period: For subscription articles, an appropriate amount of time is needed for journals to deliver value to subscribing customers before an article becomes freely available to the public. This is the embargo period and it begins from the date the article is formally published online in its final and fully citable form. Find out more.

This journal has an embargo period of 12 months.

Elsevier Researcher Academy

Researcher Academy is a free e-learning platform designed to support early and mid-career researchers throughout their research journey. The "Learn" environment at Researcher Academy offers several interactive modules, webinars, downloadable guides and resources to guide you through the process of writing for research and going through peer review. Feel free to use these free resources to improve your submission and navigate the publication process with ease.

Language (usage and editing services)

Please write your text in good English (American or British usage is accepted, but not a mixture of these). Authors who feel their English language manuscript may require editing to eliminate possible grammatical or spelling errors and to conform to correct scientific English may wish to use the English Language Editing service available from Elsevier's WebShop.

\section{Submission}

Our online submission system guides you stepwise through the process of entering your article details and uploading your files. The system converts your article files to a single PDF file used in the peer-review process. Editable files (e.g., Word, LaTeX) are required to typeset your article for final publication. All correspondence, including notification of the Editor's decision and requests for revision, is sent by e-mail.

Submit your article

Please submit your article via https://www.evise.com/profile/api/navigate/GAIPOS.

\section{PREPARATION}

Peer review

This journal operates a single blind review process. All contributions will be initially assessed by the editor for suitability for the journal. Papers deemed suitable are then typically sent to a minimum of two independent expert reviewers to assess the scientific quality of the paper. The Editor is responsible for the final decision regarding acceptance or rejection of articles. The Editor's decision is final. More information on types of peer review.

\section{Introduction}

State the objectives of the work and provide an adequate background, avoiding a detailed literature survey or a summary of the results.

1. Article types accepted are: Original Article (Full Paper or Short Communication), Review Article, Book Review. Word limits are as follows: Full Paper 3,000 words plus no more than 6 figures/ tables in total; Short Communication 1,200 words plus no more than 3 figures/tables in total.The recommended word limit for Review Papers is 6,000 words. The word limits are non-inclusive of figures, tables, references, and abstracts. If the Editor feels that a paper submitted as a Full Paper would be more appropriate for the Short Communications section, then a shortened version will be requested. References should be limited to 30 for Full Papers; and 15 for Short Papers; there is no limit for review articles. A structured abstract of no more than 300 words should appear at the beginning of each Article. Authors must state the number of words when submitting. 
Short Communications are intended to introduce new techniques that improve the analysis and evaluation of human movement. This article type is not for preliminary or case studies, and such submissions will be rejected without review. Authors submitting a Short Communication should justify why it is a Short Communication rather than a Full Paper in their cover letter. Gait and Posture does not accept case reports.

All papers should contribute to improved understanding of human movement, particularly in clinical populations, and must therefore include a statement of significance in both the structured abstract and the main text. The contribution may be methodological; however Articles that simply validate existing methods or technologies are discouraged. Validation of methodology should instead be included within a larger study in which the methodology is used to answer a clinically relevant question.

2. All publications will be in English. Authors whose 'first' language is not English should arrange for their manuscripts to be written in idiomatic English before submission. A concise style avoiding jargon is preferred.

3. Authors should supply up to five keywords that may be modified by the Editors.

4. Authors should include a structured abstract of no more than 300 words including the following headings: Background, Research question, Methods, Results and Significance. The scientific and clinical background should be explained in 1-2 sentences. One clear scientifically relevant question should be derived from the background which represents the principle research question of the paper. This should be framed specifically as a question not simply as a description. The Methods section should summarise the core study methodology including the type of study (prospective/retrospective, intervention etc), procedures, number of participants and statistical methods. The Results section should summarise the study's main findings. The Significance section should place the results into context. Furthermore this section should highlight the clinical and/or scientific importance of the work, answering the question "so what?" This section should not simply repeat the study results or conclusions.

5. Acknowledgements should be included in the title page. Include external sources of support.

6. The text should be ready for setting in type and should be carefully checked for errors. Scripts should be typed double-spaced on one side of the paper only. Please do not underline anything, leave wide margins and number every sheet.

7. All illustrations should accompany the typescript, but not be inserted in the text. Refer to photographs, charts, and diagrams as 'figures' and number consecutively in order of appearance in the text. Substantive captions for each figure explaining the major point or points should be typed on a separate sheet.

8. Tables should be presented on separate sheets of paper and labelled consecutively but the captions should accompany the

9. Authors should also note that files containing text, figures, tables or multimedia data can be placed in a supplementary data file which will be accessible via ScienceDirect (see later section for further details).

What information to include with the manuscript

Having read the criteria for submissions, authors should specify in their letter of transmittal whether they are submitting their work as an Original Article (Full Paper or Short Communication), Review Article, or Book Review. Emphasis will be placed upon originality of concept and execution. Only papers not previously published will be accepted. Comments regarding articles published in the Journal are solicited and should be sent as "Letter to the Editor". Such Letters are subject to editorial review. They should be brief and succinct. When a published article is subjected to comment or criticism, the authors of that article will be invited to write a letter or reply.

A letter of transmittal must include the statement, "Each of the authors has read and concurs with the content in the final manuscript. The material within has not been and will not be submitted for publication elsewhere except as an abstract." The letter of transmittal must be from all co-authors. 
All authors should have made substantial contributions to all of the following: (1) the conception and design of the study, or acquisition of data, or analysis and interpretation of data, (2) drafting the article or revising it critically for important intellectual content, (3) final approval of the version to be submitted.

All contributors who do not meet the criteria for authorship as defined above should be listed in an acknowledgements section. Examples of those who might be acknowledged include a person who provided purely technical help, writing assistance, or a department chair who provided only general support. Authors should disclose whether they had any writing assistance and identify the entity that paid for this assistance.

Work on human beings that is submitted to Gait \& Posture should comply with the principles laid down in the Declaration of Helsinki; Recommendations guiding physicians in biomedical research involving human subjects. Adopted by the 18th World Medical Assembly, Helsinki, Finland, June 1964, amended by the 29th World Medical Assembly, Tokyo, Japan, October 1975, the 35th World Medical Assembly, Venice, Italy, October 1983, and the 41st World Medical Assembly, Hong Kong, September 1989. The manuscript should contain a statement that the work has been approved by the appropriate ethical committees related to the institution(s) in which it was performed and that subjects gave informed consent to the work. Studies involving experiments with animals must state that their care was in accordance with institution guidelines. Patients' and volunteers' names, initials, and hospital numbers should not be used.

All Articles should include a justification of their sample size. While there is no set requirement for minimum sample size, studies considered to have too small a sample size to answer the research question will be rejected.

At the end of the text, under a subheading "Conflict of interest statement" all authors must disclose any financial and personal relationships with other people or organisations that could inappropriately influence (bias) their work. Examples of potential conflicts of interest include employment, consultancies, stock ownership, honoraria, paid expert testimony, patent applications/ registrations, and grants or other funding.

All sources of funding should be declared as an acknowledgement. Authors should declare the role of study sponsors, if any, in the study design, in the collection, analysis and interpretation of data; in the writing of the manuscript; and in the decision to submit the manuscript for publication. If the study sponsors had no such involvement, the authors should so state.

Authors are encouraged to suggest referees although the choice is left to the Editors. If you do, please supply their postal address and email address, if known to you.

Please note that papers are subject to single-blind review whereby authors are blinded to reviewers.

\section{Randomised controlled trials}

All randomised controlled trials submitted for publication in Gait \& Posture should include a completed Consolidated Standards of Reporting Trials (CONSORT) flow chart. Please refer to the CONSORT statement website at http://www.consort-statement.org for more information. The Journal has adopted the proposal from the International Committee of Medical Journal Editors (ICMJE) which require, as a condition of consideration for publication of clinical trials, registration in a public trials registry. Trials must register at or before the onset of patient enrolment. The clinical trial registration number should be included at the end of the abstract of the article. For this purpose, a clinical trial is defined as any research project that prospectively assigns human subjects to intervention or comparison groups to study the cause-and-effect relationship between a medical intervention and a health outcome. Studies designed for other purposes, such as to study pharmacokinetics or major toxicity (e.g. phase I trials) would be exempt. Further information can be found at http://www. icmje.org.

\section{Review and Publication Process}

1. You will receive an acknowledgement of receipt of the manuscript by the Editorial Office before the manuscript is sent to referees. Please contact the Editorial Office if you do not receive an acknowledgement. 
Following assessment one of the following will happen:

A: The paper will be accepted directly. The corresponding author will be notified of acceptance by email or letter. The Editor will send the accepted paper to Elsevier for publication.

B: The paper will be accepted subject to minor amendments. The corrections should be made and the paper returned to the Editor for checking. Once the paper is accepted it will be sent to production.

C: The paper will be rejected outright as being unsuitable for publication in Gait and Posture.

2. By submitting a manuscript, the authors agree that the copyright for their article is transferred to the publisher if and when the article is accepted for publication. (https://www. elsevier.com/copyright).

3. Page proofs will be sent to the corresponding author for correction, although at this stage any changes should be restricted to typographical errors. Other than these, any substantial alterations may be charged to the authors. Proofs will be sent preferably by e-mail as a PDF file (although they can be sent by overland post) and must be rapidly checked and returned. Please ensure that all corrections are sent back in one communication. Subsequent corrections will not be possible.

4. An order form for reprints will accompany the proofs.

Essential title page information

- Title. Concise and informative. Titles are often used in information-retrieval systems. Avoid abbreviations and formulae where possible.

- Author names and affiliations. Please clearly indicate the given name(s) and family name(s) of each author and check that all names are accurately spelled. You can add your name between parentheses in your own script behind the English transliteration. Present the authors' affiliation addresses (where the actual work was done) below the names. Indicate all affiliations with a lowercase superscript letter immediately after the author's name and in front of the appropriate address. Provide the full postal address of each affiliation, including the country name and, if available, the e-mail address of each author.

- Corresponding author. Clearly indicate who will handle correspondence at all stages of refereeing and publication, also post-publication. This responsibility includes answering any future queries about Methodology and Materials. Ensure that the e-mail address is given and that contact details are kept up to date by the corresponding author.

- Present/permanent address. If an author has moved since the work described in the article was done, or was visiting at the time, a 'Present address' (or 'Permanent address') may be indicated as a footnote to that author's name. The address at which the author actually did the work must be retained as the main, affiliation address. Superscript Arabic numerals are used for such footnotes.

\section{Highlights}

Highlights are mandatory for this journal. They consist of a short collection of bullet points that convey the core findings of the article and should be submitted in a separate editable file in the online submission system. Please use 'Highlights' in the file name and make sure to strictly adhere to the following specifications: include 3 to 5 bullet points (maximum 85 characters (not words), including spaces, per bullet point). See https://www.esevier.com/highlights for examples.

\section{Keywords}

Immediately after the abstract, provide a maximum of 6 keywords, using American spelling and avoiding general and plural terms and multiple concepts (avoid, for example, 'and', 'of'). Be sparing with abbreviations: only abbreviations firmly established in the field may be eligible. These keywords will be used for indexing purposes.

Formatting of funding sources

List funding sources in this standard way to facilitate compliance to funder's requirements:

Funding: This work was supported by the National Institutes of Health [grant numbers xxxx, yyyy]; the Bill \& Melinda Gates Foundation, Seattle, WA [grant number zzzz]; and the United States Institutes of Peace [grant number aaaa]. 
It is not necessary to include detailed descriptions on the program or type of grants and awards. When funding is from a block grant or other resources available to a university, college, or other research institution, submit the name of the institute or organization that provided the funding.

If no funding has been provided for the research, please include the following sentence:

This research did not receive any specific grant from funding agencies in the public, commercial, or not-for-profit sectors.

Artwork

Electronic artwork

General pointsMake sure you use uniform lettering and sizing of your original artwork.Embed the used fonts if the application provides that option. Aim to use the following fonts in your illustrations: Arial, Courier, Times New Roman, Symbol, or use fonts that look similar. Number the illustrations according to their sequence in the text.Use a logical naming convention for your artwork files. Provide captions to illustrations separately. Size the illustrations close to the desired dimensions of the printed version.Submit each illustration as a separate file.A detailed guide on electronic artwork is available.You are urged to visit this site; some excerpts from the detailed information are given here.

\section{Formats}

If your electronic artwork is created in a Microsoft Office application (Word, PowerPoint, Excel) then please supply 'as is' in the native document format. Regardless of the application used other than Microsoft Office, when your electronic artwork is finalized, please 'Save as' or convert the images to one of the following formats (note the resolution requirements for line drawings, halftones, and line/ halftone combinations given below):

EPS (or PDF): Vector drawings, embed all used fonts.

TIFF (or JPEG): Color or grayscale photographs (halftones), keep to a minimum of $300 \mathrm{dpi}$.

TIFF (or JPEG): Bitmapped (pure black \& white pixels) line drawings, keep to a minimum of $1000 \mathrm{dpi}$. TIFF (or JPEG): Combinations bitmapped line/half-tone (color or grayscale), keep to a minimum of $500 \mathrm{dpi}$.

Please do not:Supply files that are optimized for screen use (e.g., GIF, BMP, PICT, WPG); these typically have a low number of pixels and limited set of colors;Supply files that are too low in resolution;Submit graphics that are disproportionately large for the content;Supply more than 6 figures per manuscript.

\section{References}

All author names should be listed unless there are more than 6 authors, in which case the first 6 names should be listed followed by et al.

\section{Data references}

This journal encourages you to cite underlying or relevant datasets in your manuscript by citing them in your text and including a data reference in your Reference List. Data references should include the following elements: author name(s), dataset title, data repository, version (where available), year, and global persistent identifier. Add [dataset] immediately before the reference so we can properly identify it as a data reference. The [dataset] identifier will not appear in your published article.

\section{Reference management software}

Most Elsevier journals have their reference template available in many of the most popular reference management software products. These include all products that support Citation Style Language styles, such as Mendeley. Using citation plug-ins from these products, authors only need to select the appropriate journal template when preparing their article, after which citations and bibliographies will be automatically formatted in the journal's style. If no template is yet available for this journal, please follow the format of the sample references and citations as shown in this Guide. If you use reference management software, please ensure that you remove all field codes before submitting the electronic manuscript. More information on how to remove field codes from different reference management software. 
Reference style

Text: Indicate references by number(s) in square brackets in line with the text. The actual authors can be referred to, but the reference number(s) must always be given.

Example: '..... as demonstrated $[3,6]$. Barnaby and Jones [8] obtained a different result ....'

List: Number the references (numbers in square brackets) in the list in the order in which they appear in the text.

Examples:

Reference to a journal publication:

[1] J. van der Geer, J.A.J. Hanraads, R.A. Lupton, The art of writing a scientific article, J. Sci. Commun. 163 (2010) 51-59. https://doi.org/10.1016/j.Sc.2010.00372.

Reference to a journal publication with an article number:

[2] Van der Geer, J., Hanraads, J.A.J., Lupton, R.A., 2018. The art of writing a scientific article. Heliyon. 19, e00205. https://doi.org/10.1016/j. heliyon.2018.e00205.

Reference to a book:

[3] W. Strunk Jr., E.B. White, The Elements of Style, fourth ed., Longman, New York, 2000.

Reference to a chapter in an edited book:

[4] G.R. Mettam, L.B. Adams, How to prepare an electronic version of your article, in: B.S. Jones, R.Z. Smith (Eds.), Introduction to the Electronic Age, E-Publishing Inc., New York, 2009, pp. 281-304.

Reference to a website:

[5] Cancer Research UK, Cancer statistics reports for the UK. http://www.cancerresearchuk.org/ aboutcancer/statistics/cancerstatsreport/, 2003 (accessed 13 March 2003).

Reference to a dataset:

[dataset] [6] M. Oguro, S. Imahiro, S. Saito, T. Nakashizuka, Mortality data for Japanese oak wilt disease and surrounding forest compositions, Mendeley Data, v1, 2015. https://doi.org/10.17632/ xwj98nb39r. 1.

\section{Data visualization}

Include interactive data visualizations in your publication and let your readers interact and engage more closely with your research. Follow the instructions here to find out about available data visualization options and how to include them with your article.

\section{Supplementary material}

Supplementary material such as applications, images and sound clips, can be published with your article to enhance it. Submitted supplementary items are published exactly as they are received (Excel or PowerPoint files will appear as such online). Please submit your material together with the article and supply a concise, descriptive caption for each supplementary file. If you wish to make changes to supplementary material during any stage of the process, please make sure to provide an updated file. Do not annotate any corrections on a previous version. Please switch off the 'Track Changes' option in Microsoft Office files as these will appear in the published version.

\section{Research data}

This journal encourages and enables you to share data that supports your research publication where appropriate, and enables you to interlink the data with your published articles. Research data refers to the results of observations or experimentation that validate research findings. To facilitate reproducibility and data reuse, this journal also encourages you to share your software, code, models, algorithms, protocols, methods and other useful materials related to the project.

Below are a number of ways in which you can associate data with your article or make a statement about the availability of your data when submitting your manuscript. If you are sharing data in one of these ways, you are encouraged to cite the data in your manuscript and reference list. Please refer to the "References" section for more information about data citation. For more information on depositing, sharing and using research data and other relevant research materials, visit the research data page.

\section{Data linking}

If you have made your research data available in a data repository, you can link your article directly to the dataset. Elsevier collaborates with a number of repositories to link articles on ScienceDirect with relevant repositories, giving readers access to underlying data that gives them a better understanding of the research described.

There are different ways to link your datasets to your article. When available, you can directly link your dataset to your article by providing the relevant information in the submission system. For more information, visit the database linking page. 
For supported data repositories a repository banner will automatically appear next to your published article on ScienceDirect.

In addition, you can link to relevant data or entities through identifiers within the text of your manuscript, using the following format: Database: xxxx (e.g., TAIR: AT1G01020; CCDC: 734053; PDB: $1 \mathrm{XFN}$ ).

\section{Mendeley Data}

This journal supports Mendeley Data, enabling you to deposit any research data (including raw and processed data, video, code, software, algorithms, protocols, and methods) associated with your manuscript in a free-to-use, open access repository. During the submission process, after uploading your manuscript, you will have the opportunity to upload your relevant datasets directly to Mendeley Data. The datasets will be listed and directly accessible to readers next to your published article online.

For more information, visit the Mendeley Data for journals page.

Data statement

To foster transparency, we encourage you to state the availability of your data in your submission. This may be a requirement of your funding body or institution. If your data is unavailable to access or unsuitable to post, you will have the opportunity to indicate why during the submission process, for example by stating that the research data is confidential. The statement will appear with your published article on ScienceDirect. For more information, visit the Data Statement page.

\section{AFTER ACCEPTANCE}

\section{Online proof correction}

Corresponding authors will receive an e-mail with a link to our online proofing system, allowing annotation and correction of proofs online. The environment is similar to MS Word: in addition to editing text, you can also comment on figures/tables and answer questions from the Copy Editor. Web-based proofing provides a faster and less error-prone process by allowing you to directly type your corrections, eliminating the potential introduction of errors.

If preferred, you can still choose to annotate and upload your edits on the PDF version. All instructions for proofing will be given in the e-mail we send to authors, including alternative methods to the online version and PDF.

We will do everything possible to get your article published quickly and accurately. Please use this proof only for checking the typesetting, editing, completeness and correctness of the text, tables and figures. Significant changes to the article as accepted for publication will only be considered at this stage with permission from the Editor. It is important to ensure that all corrections are sent back to us in one communication. Please check carefully before replying, as inclusion of any subsequent corrections cannot be guaranteed. Proofreading is solely your responsibility.

\section{Offprints}

The corresponding author will, at no cost, receive a customized Share Link providing 50 days free access to the final published version of the article on ScienceDirect. The Share Link can be used for sharing the article via any communication channel, including email and social media. For an extra charge, paper offprints can be ordered via the offprint order form which is sent once the article is accepted for publication. Both corresponding and co-authors may order offprints at any time via Elsevier's Webshop. Corresponding authors who have published their article gold open access do not receive a Share Link as their final published version of the article is available open access on ScienceDirect and can be shared through the article DOI link.

\section{AUTHOR INQUIRIES}

Visit the Elsevier Support Center to find the answers you need. Here you will find everything from Frequently Asked Questions to ways to get in touch.

You can also check the status of your submitted article or find out when your accepted article will be published. 